\title{
Juicios y sentencias del Tribunal de la Santa Inquisición de Murcia contra ciudadanos residentes en la Corona de Aragón, desde el siglo XV al XIX
}

\author{
Judgments and sentences by the Court of the Holy Inquisition of \\ Murcia against citizens residing in the Crown of Aragon, from the \\ 15 th to the 19 th century
}

\author{
RAMÓn DOMÉNech ViLLA \\ phonascus67@gmail.com \\ Universitat d'Alacant
}

\begin{abstract}
Resumen: Durante cinco siglos, el tribunal de la Inquisicón de Murcia se encargó de juzgar los casos más diversos y realizar innumerables persecuciones, con mayor o menor intensidad y dureza, contra aquellos que se salían de la doctrina represiva marcada por la iglesia. A los supuestos delitos religiosos contra la doctrina y la fe, se unían aquellos de carácter sexual, además de los llevados a cabo contra numerosos clérigos de dudoso comportamiento e integridad ética y moral.Extraídos del catálogo publicado por Juan Bláquez Miguel en la revista Murgetana en el año 1987, teniendo como fuente principal la documentación existente en el Archivo Histórico Nacional, el estudio que se presenta analiza los juicios, sentencias y fechas que la institución de la cruz, la espada y la rama de olivo llevó a cabo contra numerosos ciudadanos que, por una causa u otra, se encontraban en territorios pertenecientes a la Corona de Aragón en el momento de ser detenidos y juzgados por diferentes motivos: judíos, musulmanes, bígamos, clérigos matrimoniados, brujas, herejes, curas que realizaban las más variadas proposiciones deshonestas para su cargo..., todos ellos forman parte de la relación que ocupará las siguientes páginas. Situaciones de lo más variado y de las que no podemos separar las más crueles sentencias imaginables.
\end{abstract}

Palabras clave: Inquisición, Murcia, procesos, Corona de Aragón

\begin{abstract}
For five centuries, this court was in charge of judging the most diverse cases and carrying out innumerable persecutions, with greater or less intensity and harshness, against those who departed from the repressive doctrine set by the church. Added to the alleged religious crimes against doctrine and faith were those of a sexual nature, in addition to those carried out against numerous clerics of questionable behavior and ethical and moral integrity. Extracted from the catalog published by Juan Bláquez Miguel in the Murgetana magazine in 1987, having as its main source the existing documentation in the National Historical Archive, the study that is presented analyzes the trials, sentences and dates that the institution of the cross, the sword and olive branch carried out against numerous citizens who, for one reason or another, were in territories belonging to the Crown of Aragon at the time of being arrested and tried for different reasons, some of them the most crazy that we can imagine today: Jews, Muslims, bigamists, married clergymen, witches, heretics, priest who made the most varied dihonest proposals for their position... all of them are part of the list that will occupy the following pages. Situations of the most varied and from which we cannot separate the most cruel sentences imaginable.
\end{abstract}

Keywords: Inquisition, Murcia, process, Crown of Aragon

\footnotetext{
* Este artículo forma parte de los trabajos del proyecto de investigación "Biografías marginales: violencia, sexo, género e identidad. Edición y análisis de las fuentes documentales valencianas de la época foral", del Ministerio de Ciencia, Innovación y Universidades del Gobierno de España (PGC2018-097011-B-I00).
} 
Ramón Doménech Villa. Juicios y sentencias del Tribunal de la Santa Inquisición de Murcia contra ciudadanos residentes en la Corona de Aragón, desde el siglo XV al XIX

\section{Contextualización}

El 1 de noviembre de 1478 el papa Sixto IV promulgaba la bula Exigit sinceras devotionis affectus por la que quedaba creada la Inquisición dentro del ámbito de la corona de Castilla y autorizaba el nombramiento de inquisidores a los monarcas con poder en el territorio correspondiente. Dos años después, 27 de septiembre de 1480, se procedía, en las personas de Miguel de Morillo y Juan de San Martín, a la designación de los primeros, cuya misión inicial, al menos en apariencia, fue la detección y extinción de los focos de judíos conversos que se habían detectado en la diócesis de Sevilla por parte del dominico Alonso de Ojeda (Joseph 2012; Kamen 2011).

En la Corona de Aragón, Fernando el Católico consiguió que el papa nombrase al dominico Tomás de Torquemada, ${ }^{1}$ el 17 de octubre de 1483, Inquisidor General para Aragón, Valencia y Cataluña. En pocos años, el Tribunal del Santo Oficio se convirtió en colaborador necesario para la implantación de la política de sibilina represión decretada por la monarquía de los Reyes Católicos, bajo la óptica de diferentes posibilidades religiosas, políticas y económicas: la unidad religiosa, y la correspondiente intervención de los monarcas en este ámbito; el sometimiento de los posibles rivales y opositores políticos, con la excusa de exterminar a la minoría judeoconversa; y el enriquecimiento de las arcas del reino, gracias a la confiscación de los bienes de los acusados (Joseph 2012).

La institución inquisitorial, que no había sido una creación exclusiva española y cuyos orígenes se remontan a la bula Ad abolendam, promulgada por el papa Lucio III en el siglo XII con la vista puesta en la lucha contra la herejía albigense en el sur de Francia, pasó, a lo largo de sus más de tres siglos de existencia en España, por diferentes períodos hasta su abolición definitiva el 15 de julio de 1834 durante la Regencia de María Cristina de Borbón (Martín 1980).

Diez años después de su creación en territorio castellano, en 1488, la ciudad de Murcia asistió al establecimiento de una de las diferentes sedes fijas del Tribunal Permanente de la Inquisición, dependiente del denominado Consejo de la Suprema y General Inquisición. Años antes, las ciudades de Sevilla, Córdoba, Toledo, junto al municipio pacense de Llerena, fueron partícipes de decisiones administrativas similares.

Este Tribunal emplazado en la ciudad de Murcia tenía sus competencias sobre las jurisdicciones que formaban parte del obispado de Cartagena. Es de destacar la relación de colaboración que se estableció con el Tribunal de las mismas características creado en Cuenca en 1489. En este sentido, señalar que el tribunal murciano llegó a tener atribuciones sobre la ciudad guadalajareña de Sigüenza, a lo que hay que añadir la asistencia que se estableció respecto a la gestión de alguno de los procesos de lo que hoy en día conocemos como la Diócesis de Orihuela-Alicante, creada como tal el 14 de julio de 1564. La inquisición instalada en Murcia también administró la justicia correspondiente al arciprestazgo de Alcaraz, que se había separado del de Córdoba en 1533, a lo

1 Torquemada, 1420 - Ávila, 1498.

SCRIPTA, Revista internacional de literatura i cultura medieval i moderna, núm. 15 / juny 2020 / pp. $175-214$ ISSN: 2340-4841 · doi:/ SCRIPTA.16.19250 
que hay que añadir la jurisdicción de los asuntos pertinentes, desde 1525, de lo que hoy sería el territorio argelino de Orán (Morales 1977).

El núcleo de este artículo está basado en la recopilación realizada por Blázquez Miguel (1987), quien, tras un detallado estudio, nos muestra una catalogación de los procesos correspondientes, por nombre y apellido de los juzgados, junto a la localidad de residencia del acusado en el momento de ser detenido, el año o años en los que se desarrolló el proceso, así como la sentencia -siempre que fuera posible-, incluyendo la referencia de legajo correspondiente, relativo a los fondos del Tribunal del Santo Oficio de Murcia que se encuentran, en su inmensa mayoría, en al Archivo Histórico Nacional.

Según lo indicado en líneas anteriores, y por diferentes motivos, muchos de los encausados y encausadas que se recogen en la distinta documentación recopilada fueron ciudadanos con residencia en localidades pertenecientes en ese momento al Reino de Valencia.

El objetivo principal de este trabajo es profundizar en esos reos y sus correspondientes procesos inquisitoriales, teniendo en cuenta su lugar de procedencia, tipo de delitos cometidos y los veredictos realizados. Además, dentro de lo posible, se ampliará la información de alguno de ellos añadiendo la documentación encontrada en el Portal de Archivos Españoles (PARES), ${ }^{3}$ algo que nos permitirá una visión más detallada de los tipos, motivos y sentencias dictadas contra estos sujetos que forman parte de un pasado marcado por cada una de sus particulares «biografías marginales».

De esta manera, bígamos, fornicarios, blasfemos, judaizantes e islamitas, entre otros, cada uno y cada una dentro de sus particulares circunstancias y contextos sociales, quedarán recogidos en las próximas páginas a través de diferentes clasificaciones que impliquen datos detallados para un análisis y conclusiones más profundas, utilizando como criterio selectivo su lugar de residencia o las sentencias humillantes que les fueron aplicadas en su momento y que arrastraron, en un importante número de casos y durante muchos años posteriores dentro de un singular concepto de «solidaridad compartida», sus descendientes directos más cercanos.

\section{Primer acercamiento}

El trabajo de Blázquez Miguel (1987) recogía en su clasificación veinte grupos principales para la identificación de cada uno de los procesos y la correspondiente unidad documental. En algunos de ellos, en tres en concreto, añadía diferentes subgrupos. ${ }^{4}$ De esta manera el III lo formaban los solicitantes, flagelantes, celebrantes de misa sin estar ordenados, junto a los religiosos casados. En

2Debido a las características de la documentación conservada, que afecta a la correspondiente digitalización, aquellos a los que hemos tenido acceso se encuadran, sobre todo, en los siglos XVIII y XIX.

3 http://pares.culturaydeporte.gob.es/inicio.html

4Siempre teniendo en cuenta lo que el autor señala al principio de su catálogo: «Por tanto solo puedo dar, en muchas 
Ramón Doménech Villa. Juicios y sentencias del Tribunal de la Santa Inquisición de Murcia contra ciudadanos residentes en la Corona de Aragón, desde el siglo XV al XIX

el grupo IV incluía a los bígamos y fornicarios. Y en el grupo VIII los juzgados por proposiciones, los blasfemos y el de aquellos llevados ante el tribunal por motivos de palabras.

De toda esta amplia clasificación, y debido a los objetivos de este artículo, para este estudio se han seleccionado los pertenecientes a los siguientes grupos:

- Islamitas.

- Judaizantes.

- Solicitantes.

- Religiosos casados.

- Bígamos.

- Fornicarios.

- Supersticiosos.

- Blasfemos.

- Sacrílegos.

- Irreverentes.

- Delitos contra el Santo Oficio.

- Delitos desconocidos.

Para esta primera aproximación se ha optado por contabilizar el número total de casos en cada uno de los grupos de estudio y extraer aquellos juicios que afectarían a nuestro ámbito de interés. El objetivo es tener una visión inicial del número de encausados que fueron juzgados por el Tribunal con sede en Murcia y que tenían su residencia ${ }^{5}$ en territorios bajo la jurisdicción de la Corona de Aragón.

Uno de los grupos más numerosos, como era de esperar debido a las competencias adquiridas por el Tribunal y sus pretensiones iniciales, es el de los acusados por cuestiones relacionadas con profesar el islamismo en sus respectivos ámbitos privados. De esta manera, observamos cómo, de los poco

ocasiones, el número del legajo y la fecha, concretada en el año, salvo excepciones, del documento. (...) Debido a que prácticamente no existe un solo proceso completo...» (Blázquez Miguel 1987: 6).

5 Un concepto de residencia que afectará también a casos particulares, como el de aquellos que estaban de paso en una localidad determinada pero que cometieron el acto delictivo dentro de este ámbito territorial que nos interesa o el de aquellos encausados que, además del delito del que se les acusaba por el Tribunal, ya se encontraban en prisión por algún delito previo. 
Ramón Doménech Villa. Juicios y sentencias del Tribunal de la Santa Inquisición de Murcia contra ciudadanos residentes en la Corona de Aragón, desde el siglo XV al XIX

más de mil casos juzgados por esta causa, doscientos dieciséis corresponden a poblaciones del Reino de Valencia, a los que se añaden, tal vez por cuestiones relacionadas por el lugar donde se produce la detención del acusado, el de un ciudadano con residencia en Tarragona y cinco en las Islas Baleares -Ibiza, Mallorca y Menorca. Con posterioridad veremos los casos más significativos, así como las zonas geográficas más afectadas, junto a otros datos de interés: fechas, sentencias, situación social...

El segundo grupo en número de casos juzgado por el Tribunal del Santo Oficio de Murcia lo compuso el de los judaizantes con poco más de ochocientas vistas realizadas a lo largo de los diferentes siglos. De ellos, sesenta son de nuestro ámbito de interés. A simple vista, sin entrar por el momento en mayor número de detalles, llama la atención todos aquellos juzgados procedentes de Portugal. Una cuestión que, además de lo señalado en la relación correspondiente de los juicios individuales, se constata al observar alguno de los apellidos: Andrade, Figueroa...

Cerca de trescientos cincuenta casos confirmados de clérigos que solicitaban favores sexuales durante la confesión están confirmados gracias a la relación existente de los mismos, con mayor o menor detalle. Además de lo que puede suponer este tipo de delitos en un estamento de las características de lo señalado, estos datos nos informan sobre el control que se ejercía a sus miembros por parte del Tribunal. Sesenta y nueve es el número de eclesiásticos que aparecen dentro de la selección que se ha hecho. A simple vista no hay siglo ni orden religiosa que se salve en esta relación: capuchinos, sacerdotes, dominicos, carmelitas, trinitarios... Por lo tanto, un significativo número de parroquias, conventos, etc. de la diócesis de Orihuela-Alicante -según lo explicado en líneas anteriores y teniendo en cuenta la pertenencia por fechas- fueron afectadas por este tipo de delitos y de clérigos llevados ante el Santo Oficio con su correspondiente acusación.

Catorce son los eclesiásticos que aparecen referenciados y que se casaron sin poder hacerlo. Tres de ellos fueron detectados y llevados a juicio, con sus correspondientes penas por cometer el delito.

Cerca de trescientos acusados, de ambos sexos, comparecieron durante más de trecientos años ante el Tribunal para defenderse del delito de bigamia. Cuarenta de esta relación procedían del ámbito de la Corona de Aragón. Los castigos, de todo tipo como comprobaremos más adelante, se pueden observar a la hora de analizar uno por uno los casos.

De los más de ciento diez casos recogidos y contrastados en el catálogo, donde no faltan mujeres, aunque en una cantidad menor que las relacionadas en el bloque anterior, es posible comprobar la presencia de diecinueve vecinos residentes en distintas localidades de las actuales comarcas de la Vega Baja o el Bajo Vinalopó, dentro del apartado de fornicarios. En esta sección también se incluían los relativos a la sodomía, coito anal homosexual o heterosexual, y al bestialismo. Estos aparecían dentro del ámbito de la Inquisición y sus competencias por considerarse contra naturam según el Derecho Canónico. Llamaba la atención comprobar que, a partir del 1524 y según lo dictaminado por Clemente VII, la Inquisición aragonesa era la competente para juzgar los casos de sodomía estuviesen relacionados o no con el delito de herejía. Una cuestión que en Castilla y sus 
Ramón Doménech Villa. Juicios y sentencias del Tribunal de la Santa Inquisición de Murcia contra ciudadanos residentes en la Corona de Aragón, desde el siglo XV al XIX

tribunales solo llevada a juicio si tenía relación con cuestiones heréticas. Tal vez, por ese motivo, el único caso con fuentes documentales digitalizadas, ${ }^{6}$ el de Francisco Rocamora en el año 1734, originario de Orihuela, fue enviado por el tribunal de Murcia al de Valencia para que fuera juzgado.

El número de supersticiosos procedentes dela zonageográfica analizada es mayor, proporcionalmente, que en el resto de grupos analizados: setenta y nueve, de un total de poco más de trescientos. Este hecho, junto a una relación importante de inculpados durante el siglo XVIII, facilitará también que sea uno de los más documentados con los fondos del archivo.

Cuarenta y un procesados por blasfemos y blasfemas, de los casi trescientos relacionados, forman parte de la relación existente en el catálogo. Una nómina que estaba formada por aquellos que eran sospechosos de cualquier aseveración que se pudiera calificar como delito verbal. Una simple afirmación en cualquiera de los ámbitos de la vida social, casi siempre relacionada con el ámbito sexual o de las creencias religiosas, era suficiente para el inicio de una causa por parte del Tribunal. Una lista menor de inculpados por el Santo Oficio la componen los restantes grupos del registro.

De esta manera encontramos una decena de los mismos por cuestiones de sacrilegio, repartidos sobre todo entre los siglos XVII y XVIII. Apenas tres acusados por irreverencia, cuando el total no llega a treinta. Una docena de enjuiciados por cometer delitos contra el Santo Oficio, incluidos cinco clérigos de diferentes órdenes religiosas. Cinco por delitos varios, entre los que llaman la atención el de «desacato», el de «escribir un libro»-que fue el cometido por el oriolano juzgado en 1707 Tomás Martínez y castigado con seis años de destierro- o exhortar a la rebelión. Caso este del franciscano con domicilio en el municipio de Elda, juzgado en 1709, Urbano Moltó. Como última categoría encontramos clasificados desde el siglo XVI hasta el XIX -casi coincidiendo con la disolución del Tribunal del Santo Oficio- aquellos cuyo delito o delitos son desconocidos. Una veintena, entre hombres y mujeres, forman parte de esta relación.

\section{Profundización de los casos juzgados: quiénes, dónde, cuándo y sus sentencias}

En las siguientes secciones se analizarán de forma más detallada cada uno de los casos juzgados en su momento por el Tribunal. Para ello se tomarán como referencia aquellas cuestiones relacionadas con las localidades indicadas en el catálogo de Blázquez Miguel (1987), el año de la celebración del juicio y la sentencia dictada. Cuando aparezca por primera vez alguna de estas sentencias se ampliará en qué consistía y el porqué. De esta manera tendremos un primer acercamiento a cada una de ellas y será posible, con posterioridad, analizar cuáles fueron las más comunes y aplicadas a cada tipo de delito, junto a su imposición según las distintas fechas en las que fueron dictadas.

Varias eran las posibilidades para ordenar cada uno de los juicios tratados. Analizados los objetivos de este artículo, y a la vista de los listados, se ha elegido hacerlo por orden alfabético de la localidad

6 http://pares.mcu.es/ParesBusquedas20/catalogo/description/3707807?nm 
Ramón Doménech Villa. Juicios y sentencias del Tribunal de la Santa Inquisición de Murcia contra ciudadanos residentes en la Corona de Aragón, desde el siglo XV al XIX

que aparece como lugar de procedencia del juzgado, junto a las fechas de celebración de las audiencias. Una vez seleccionados y extraídos, se señalará cualquier otro dato que se estime de interés y sea significativo para la ampliación del estudio.

\subsection{Islamitas}

Ocho sentencias -las de dos mujeres y seis hombres- aparecen relacionadas con el municipio alicantino de Albatera. Todas ellas dictadas en el siglo XVI -durante los últimos catorce años del siglo, si queremos ser más precisos-. Las condenas a galeras -entre cuatro y cinco años en este caso-, los azotes -entre cien y doscientos-, junto al destierro y años de cárcel fueron los fallos dictados.

La condena a galeras -remeros en la marina militar-, creada en su momento por Fernando el Católico con un claro objetivo de encontrar mano de obra barata, tenía, dicho con buenas palabras, la finalidad de que los reos cumplieran su pena realizando una actividad «útil» para la Corona. Podemos imaginar que aquellos que recibían esta condena, posteriormente denominados galeotes una vez dispuestos en su emplazamiento en el barco, debían de cumplir unas condiciones físicas determinadas. Así que, aunque no aparezca en la relación de juzgados, tenían que ser hombres que físicamente pudieran ser utilizados para los objetivos de estos veredictos que, además, ocultaban una particular visión de la esclavitud, junto un ahorro económico a las arcas correspondientes de la Real Hacienda (Kamen, 2011).

En este primer grupo también podemos ver cómo era común condenar a los acusados a la pena de azotes. Un castigo físico de clara reminiscencia dentro del cristianismo y que podemos completar visualmente con las imágenes de la Pasión de Cristo, según las descripciones que aparecen en los diferentes pasajes del Nuevo Testamento. Según Kamen (2011) era aplicada a personas de bajo estatus social. Podemos imaginar la dureza del tipo de pena y lo que significaba tanto física como psíquicamente. Además, como era típico en cualquier sentencia dictada en este contexto, llevaba consigo otras consecuencias; como la deshonra a través de las «particulares procesiones populares» que se realizaban por las calles de la ciudad, y que contaban con la participación activa de los espectadores. ${ }^{7}$ Llama la atención la no existencia de diferencias para la aplicación de este tipo de condena, que lo mismo podía afectar a niños y niñas que a hombres o mujeres o jóvenes y ancianos. La pena de azotes podía ser una opción alternativa para aquellos que, por los diferentes motivos expuestos, no podían ser condenados a galeras.

\footnotetext{
7 Sin duda se trataba de un acto de expresión de vergüenza pública. Debemos recordar que los condenados a este o a otro cualquier tipo de pena, además de lo ya indicado, se presentaban ante la ciudadanía, cuando acudían al auto de fe, ataviados de los más diversos accesorios humillantes. En el caso de los condenados a azotes aparecían con una soga al cuello con tantos nudos como latigazos iban a recibir durante su deshonroso paseo -cada nudo equivalía a un centenar. En algunos casos los condenados también llevaban la denominada coroza; un gorro con forma cónica que servía de complemento al ya humillante sambenito que portaban los condenados a modo de hábito que cubría su cuerpo y sobre el que también existían diferentes «modelos» que fueron cambiando con el paso del tiempo, el tipo de herejía por el que eran condenados... (Pérez 2012).
} 
Ramón Doménech Villa. Juicios y sentencias del Tribunal de la Santa Inquisición de Murcia contra ciudadanos residentes en la Corona de Aragón, desde el siglo XV al XIX

Veintitrés casos de vecinos de la ciudad de Alicante fueron juzgados, según los datos existentes, durante tres siglos por el delito que nos ocupa. Además de las sentencias ya indicadas, dentro de la horquilla relativa al número que era posible aplicar-azotes, años de cárcel, destierro...-, llama la atención la presencia de dos de los tres tipos de abjuras que aparecen dictaminadas por los tribunales del Santo Oficio. Nos estamos refiriendo a las abjuras de levi y de vehementi. La tercera de ellas, la denominada «en forma» no aparece en la relación de las impuestas a estos sentenciados. Según lo indicado por Pérez (2012) era posible diferenciar distintas categorías entre los acusados: los que el tribunal pensaba que lo eran, aunque no tenían pruebas para llevar a cabo la acusación correspondiente; aquellos que se declaraban culpables y los denominados «pertinaces» o reincidentes, que incluso llegaban a negar su culpabilidad herética aún con la existencia de pruebas en su contra.

Para los dos primeros grupos existía la posibilidad de retractarse del delito y reconciliarse a pesar de la falta cometida. En este caso se aplicaba alguna de las dos penas señaladas. La abjuración de levi podíamos definirla como la más leve de los dos. Era, por decirlo de alguna manera, para los sospechosos de delitos heréticos menores. El castigo podía ser una especie de «penitencia» particular: ayunos, oraciones, peregrinaciones... Los condenados por abjuración de vehementi, sospechosos a pesar de las pruebas y que se negaban a confesar, eran castigados a unas penas mayores, algunas de ellas ya señaladas: destierro, flagelación, galeras, prisión... Aunque no se observa entre los condenados y condenadas procedentes de la localidad de Alicante ninguna abjuración «en forma», si es bueno señalar, para posteriores casos, que estaba reservada para aquellas situaciones más graves en las que los acusados habían sido declarados culpables y habían confesado. Se trata de una situación común para los juzgados por judaizantes (Pérez 2012).

Una figura que no podemos olvidar es la de los denominados «relapsos». Estamos hablando de los reincidentes. De estos había dos tipos: penitentes e impenitentes. En otras palabras, los que reconocían su delito y los que no. En ambos casos la pena solía ser la muerte. La diferencia consistía en que los primeros solían ser estrangulados antes de ser quemados -garrote vil- y los segundos eran ejecutados en la hoguera con vida, castigo impuesto por no haberse arrepentido. Sin duda, y siguiendo lo señalado por Pérez (2012), estos últimos significaban el mayor fracaso para los inquisidores; pues no habían cumplido con el objetivo de conducirles al arrepentimiento y reconocer el error que habían cometido, a pesar de su vía libre para someterlos a cualquier tipo de tortura que estuviese en sus manos para conseguir estas pretensiones.

Una vez dentro de los casos analizados, se puede señalar la presencia de ocho juzgados (7 hombres y 1 mujer) en los que aparece la clasificación de «esclavos», la gran mayoría de ellos llevados al tribunal en 1588. Además, observamos la existencia de, aunque residentes o procedentes de Alicante de una manera u otra, encausados en este apartado de origen francés, portugués e italiano. De esta última nacionalidad destacamos el caso de Felipe Luis José Arbico, juzgado en el año $1750{ }^{8}$ No existe constancia de sentencia en el censo estudiado, pero encontramos su expediente digitalizado,

8 Fecha sobre la que Blázquez Miguel (1987) expresa sus dudas al colocarla entre signos de interrogación. 
Ramón Doménech Villa. Juicios y sentencias del Tribunal de la Santa Inquisición de Murcia contra ciudadanos residentes en la Corona de Aragón, desde el siglo XV al XIX

encabezado por las acciones del «Fiscal de Murcia», según aparece en el archivo correspondiente, en el que se puede leer la decisión judicial de la continuidad de su sentencia en prisión a la que se añade el «embargo de sus bienes si los tiene». A esto hay que añadir la nota sobre su encausamiento en el apartado de «alcance y contenido» de la catalogación correspondiente: «natural de Italia, presidiario en Alicante, seguido en el Tribunal de la Inquisición de Murcia, por apóstata». En relación con esta causa podemos añadir que, ante las dudas manifestadas por Blázquez relativas a las fechas del juicio, que en el expediente se observa la siguiente anotación: «Apuntamientos de causas de Fe y civiles de 18?? Y 1820», por lo que es entre esas dos referencias temporales en las que podemos datar el caso correspondiente y solucionar el tema sobre el que Blázquez Miguel planteaba dudas.

Llamativos son los cuarenta procesos que tuvieron como origen el municipio alicantino de Aspe, casi todos en el siglo XVI. En ellos encontramos sentencias ya conocidas y algunas que especifican la cantidad económica impuesta como sanción -expresada en maravedíes y ducados. Son dignos de reseñar tres casos, tal vez juzgados conjuntamente, del 1588. Nos referimos a los de Rodrigo Fajar, José Mandado y Francisco Martínez. Todos ellos condenados a «relajación». ${ }^{10}$ Respecto a esta sentencia decir que era lo que llamamos en la actualidad «Pena Capital» y que se castigaba con la ejecución pública de la sentencia señalada. Es decir: muerte en la hoguera. La Inquisición como tal no podía ejecutar este tipo de sentencias, por ese motivo entregaba a los condenados a los denominados Tribunales Reales. En otras palabras «relajaba a los reos al brazo seculan». Aquellos que habían reconocido su pena penitentes- tenían derechos a ser ajusticiados mediante la técnica del garrote vil, antes de ser quemados. El otro grupo, los impenitentes, eran quemados vivos. Añadir que este acto de la quema o ejecución de la condena se realizaba con posterioridad al correspondiente auto de fe público. Los condenados, una vez finalizado este, eran llevados a otro lugar donde se ejecutaba el castigo impuesto (Pérez, 2012).

Hay una cuestión previa que aún ahonda más en esta desagradable cuesión. Nos referimos a la conocida como «relajación en efigie». En otras palabras, hablamos de la ejecución de un muñeco o similar que representaba al condenado, que o bien había sido juzgado en lo que en términos jurídicos se conoce como in absentia o que había fallecido durante el procedimiento judicial, y se producía su simbólica quema. ${ }^{11}$ Es evidente que poco más hay que añadir sobre este asunto tan sumamente desagradable.

Debido a la fecha en la que se produjo la ejecución de los tres condenados señalados en el párrafo anterior, es conveniente referirnos a las afirmaciones de Morales y Marín (1977). En ellas, y en relación con el Tribunal de la Inquisición de Murcia, nos indica que:

9 http://pares.mcu.es/ParesBusquedas20/catalogo/description/3743513?nm.

10 En la quinta acepción del DRAE aparece el siguiente concepto: «Dicho de un juez eclesiástico: entregar al secular un reo digno de la pena capital». Destaca su origen del latín relax $\square$ re. Nos estamos refiriendo al acto de relaja o entregar (dejar en manos de alguien). En este caso al estamento civil competente.

11 Según señala Pérez (2012), el motivo de estas condenas estaba justificado por entenderse la herejía como un crimen de lesa majestad. En el caso que nos ocupa, se producía relativo a Dios. Este tipo de delitos estaban castigados con la pena de muerte.

SCRIPTA, Revista internacional de literatura i cultura medieval i moderna, núm. 15 / juny 2020 / pp. 175-214 ISSN: 2340-4841 · doi:/ SCRIPTA.16.19250 
Ramón Doménech Villa. Juicios y sentencias del Tribunal de la Santa Inquisición de Murcia contra ciudadanos residentes en la Corona de Aragón, desde el siglo XV al XIX

\begin{abstract}
En el plazo de once años, 1557 a 1568, fueron llevados a la hoguera en Murcia 154 personas vivas y 52 en efigie. (...) El 7 de junio de 1577 eran llevadas a la hoguera once personas. El 12 de febrero de 1559 la escalofriante suma de treinta murcianos perecían entre terribles gritos. El 4 de febrero de 1560 eran catorce los que sufrían la pena capital. El 8 de septiembre de este mismo año dieciséis personas. Y, por último, entre las matanzas en serie anotamos la del $15 \mathrm{de}$ marzo de 1562 con veintitrés víctimas del "brasero" y la del 20 de mayo de 1563 con diecisiete.
\end{abstract}

Por lo tanto, estas tres ejecuciones señaladas se produjeron dentro de esos terribles 11 años que fueron señalados como turbadores en la ciudad de Murcia debido al gran número de ejecutados.

Entre la relación de los vecinos de Aspe facilitada por Blázquez Miguel (1987) llama la atención el nombre de Juan Alacayo quien, según los archivos consultados, ${ }^{12}$ ya había sido juzgado en un auto de fe, junto a un importante número de condenados entre los que destacaban el núcleo de los acusados por luteranismo, «celebrado en la plaza del Borne en Barcelona en 1564 por delitos de blasfemias y agravios al Santo Oficio».

Los habitantes del municipio de Ayora también fueron juzgados por el tribunal con sede en Murcia durante el período aproximado de los tres siglos y medio en los que la Inquisición ejerció su particular justicia. Puede resultar curioso que esta localidad aparezca en la relación del catálogo, de forma repetida, cuando pertenece la provincia de Valencia. Sin embargo, el hecho de que a la diócesis de Orihuela se le hubiera concedido por parte del papa Martín V (28-11430 $)^{13}$ el vicariato general foráneo correspondiente a la parte de la diócesis de Cartagena que pertenecía al Reino de Valencia y que, en consecuencia, incluía el arciprestazgo de Ayora, parece que encontramos la justificación sobre la competencia en estos acusados del Tribunal con sede en Murcia ${ }^{14}$ (Carpio, Sainz et al. 1999), al igual que en otras situaciones similares que se puedan presentar. Los casos de islamitas enjuiciados en dicha localidad, y que aparecen en la relación, fueron ocho. Todos ellos, menos uno que fue en 1588, celebraron su juicio en el mismo año: 1580, y encontramos sus datos en el mismo número de legajo: 2022/10; de ninguno de ellos se conserva la información sobre la sentencia dictada. También resultan llamativos los nombres de los encausados, pues de ellos podemos suponer el origen de los mismos: Duayma, Hubeen, Humeite, Zumeize...

Otros municipios de la actual provincia de Valencia y que aparecen en la nómina de acusados, son los de Chiva, Tabernes, la propia ciudad de Valencia ${ }^{15}$ y Ollería. De esta última localización

12 http://pares.mcu.es/ParesBusquedas20/catalogo/description/6733798?nm.

13 A petición del futuro papa Calixto III -Alfonso de Borja-, del ayorino Miguel Molsós -pavorde y posteriormente nombrado responsable de la jurisdicción- y del rey Alfonso V de Aragón.

14 El arciprestazgo de Ayora sería agregado a la archidiócesis de Valencia el 13-3-1954.

15 Juan Bautista Navarro (absuelto), José Pérez (500 azotes y galeras a perpetuidad), José Real (absuelto), Francés Arbí (200 azotes y 10 años en galeras) y Juan Catalán (relajado). Sobre estos dos últimos Blázquez Miguel (1987) muestra sus

SCRIPTA, Revista internacional de literatura i cultura medieval i moderna, núm. 15 / juny 2020 / pp. 175-214 ISSN: 2340-4841 ·doi:/ SCRIPTA.16.19250 
Ramón Doménech Villa. Juicios y sentencias del Tribunal de la Santa Inquisición de Murcia contra ciudadanos residentes en la Corona de Aragón, desde el siglo XV al XIX

era Joaquín Cerdá, juzgado por el tribunal en 1754, y del que también podemos acceder a su expediente digitalizado. ${ }^{16}$ En este caso, las notas sobre los datos descriptivos son significativas al leer la sección «alcance y contenido». En ellas encontramos el sobrenombre, origen y profesión del juzgado: «Alegación fiscal del proceso de fe de Joaquín Cerda, alias «Solimán», natural de Ollería, barbero, seguido en el Tribunal de la Inquisición de Murcia, por renegado».

La relación de municipios pertenecientes a la Vega Baja del Río Segura, se completa con los siguientes: Cox -4 casos-, Granja de Rocamora -2 casos-, Orihuela -10 casos-. La gran mayoría de ellos datados durante el siglo XVI. El caso de Orihuela es significativo por la existencia de tres esclavos entre la relación de nombres, todos ellos en el siglo XVII, y con sentencias leves si las comparamos con las anteriormente señaladas.

En referencia a la comarca del Bajo Vinalopó podemos destacar los quince procesos realizados contra vecinos originarios del municipio de Crevillente -todos, menos uno, tuvieron lugar en el siglo XVI-, a los que podemos unir los dieciséis con reos procedentes de Elche.

De las diferentes sentencias que nos aporta esta nueva relación de juzgados, hay que destacar la de los denominados «reconciliados», una nueva categoría que, según lo señalado por Pérez (2012), podía ser fallada en aquellos casos más leves -acompañada normalmente de la correspondiente abjuración de levi o de vehementi-, y que reconocían su pena -convictos o confitentes- o alegaban su inocencia, y para los que no existían pruebas inculpatorias claras. Con esta sentencia, el acusado se podía reintegrar a la Iglesia una vez realizada la correspondiente abjuración. A pesar de todo, estos condenados eran marcados para toda su vida, tanto ellos como las dos generaciones posteriores hijos y nietos- y, junto a la acusación, arrastraban las penas de no poder ocupar cargos eclesiásticos, empleos públicos o algunas profesiones de relevancia: médico, farmacéutico, recaudador de impuestos... Como suele ser habitual en contextos similares, esta supuesta inhabilitación heredada podía perdonarse a cambio de un particular concepto de multa, llamada de «composición».

Una relación importante de casos, también por su extensión, es la que se sitúa en el Medio Vinalopó. Además de los descritos para el caso del municipio de Aspe, las poblaciones de Elda -24 casos durante el siglo XVI-, Monforte -2 casos datados en el siglo XVI-, Novelda -19 enjuiciados durante los siglos XVI y XVII-, Petrel -con 4 juzgados en el siglo XVI- y Monóvar ${ }^{17}-17$ casos entre los siglos XVI y XVII-, se añada a la relación de aspenses citada con anterioridad. Sobre los procedentes de este último municipio es de destacar la celebración de juicios conjuntos, a la vista de lo señalado por Blázquez Miguel (1987). Estos fueron realizados durante el año 1603, de los que podemos confirmar 9 enjuiciados en las mismas fechas. También llama la atención el de

dudas relativas a la ciudad de procedencia, aunque lo incluiremos en Valencia.

16 http://pares.mcu.es/ParesBusquedas20/catalogo/description/3741467?nm.

17 De este municipio procedía el relajado más tardío que hemos encontrado en el catálogo. Se trata de Juan Ruiz de Villena, vecino de Monóvar ajusticiado en el año 1683 por la autoridad correspondiente.

SCRIPTA, Revista internacional de literatura i cultura medieval i moderna, núm. 15 / juny 2020 / pp. 175-214 ISSN: 2340-4841 · doi:/ SCRIPTA.16.19250 
Ramón Doménech Villa. Juicios y sentencias del Tribunal de la Santa Inquisición de Murcia contra ciudadanos residentes en la Corona de Aragón, desde el siglo XV al XIX

los tres relajados con el mismo apellido y, según el investigador, es posible que coincidentes en el tiempo: Aldonza Ruiz, Blanca Ruiz y Pedro Ruiz, a los que les esperó el mismo y fatídico final por sus delitos.

Por relativa cercanía, aunque en la actualidad en diferentes comarcas, se puede incluir a las dos acusadas originarias del Alto Vinalopó, en concreto de la ciudad de Villena, y que aparecen con los nombres de María y María Solac; ambas encausadas, sentenciadas y reconciliadas en el 1612.

La relación de juzgados se completa con un número menor de encausados procedentes de diferentes municipios. Jalón, perteneciente a la Marina Alta (Alicante), con dos casos a finales del siglo XVI. La localidad de Teresa, en la comarca del Alto Palancia (Castellón), con dos casos de absolución en el 1615. Tres casos datados en fechas muy cercanas, finales del siglo XVI, en el municipio alicantino de Polop de la Marina (Marina Baja). A los que añadir una absolución de un ciudadano tarraconense en 1656; dos procedentes de Ibiza entre el 1585 y 1587; un mallorquín reconciliado en el año 1594; y dos menorquines en el año 1664 -reconciliado uno y sin sentencia reconocida el otro-. A todos estos podíamos sumar el procedente de una localidad que Blázquez Miguel (1987) señala como «Rolleo» -entre interrogación-, y que podría tratarse del municipio alicantino comarca de la Marina Baja- de Relleu. Aquí residiría el ciudadano Pascual Gaspar, sentenciado en 1620 a la pena de 200 azotes y a cumplir 4 años en galeras.

\subsection{Judaizantes}

Las poblaciones que presentan casos juzgados por la persecución llevada contra a aquellos que incitaban a judaizarse a los conversos, aparecen en un número menor que las del grupo anterior. Esto no quiere decir que los juicios realizados fueran menos proporcionalmente, aunque sí más concentrados por las características y el total de los afectados. Un simple análisis de las fechas que aparecen en el catálogo estudiado nos indica que los tres siglos (XV, XVI y XVII) estuvieron plenos de este tipo de acciones por parte de la Inquisición.

Las penas que se impusieron, en mayor o menor cantidad en lo relativo al número de azotes, años de destierro, cárcel o similares, coinciden con las de la sección anterior en aquellos casos en los que aparecen señaladas las sentencias correspondientes. Es cierto que no se observa ningún caso de envío a galeras o de abjura, aunque esto no quiere decir nada, puesto que existe un número importante de casos donde no se especifican las correspondientes condenas.

Quince juicios por el motivo señalado en este apartado se realizaron contra ciudadanos originarios de Alicante. Es posible observar alguno de ellos aún en el siglo XVIII -cinco en concreto-. Entre ellos podemos destacar, por estar contrastado con la digitalización del archivo en cuestión, el de la portuguesa Guiomar de Andrade ${ }^{18}$ y su marido Francisco de Paz, fechado en 1721 en el "proceso de fe de Guiomar de Andrade, mujer de Francisco de Paz, originaria de Alicante, seguido en el

18http://pares.mcu.es/ParesBusquedas20/catalogo/description/3703857?nm.

SCRIPTA, Revista internacional de literatura i cultura medieval i moderna, núm. 15 / juny 2020 / pp. 175-214 ISSN: 2340-4841 · doi:/ SCRIPTA.16.19250 
Ramón Doménech Villa. Juicios y sentencias del Tribunal de la Santa Inquisición de Murcia contra ciudadanos residentes en la Corona de Aragón, desde el siglo XV al XIX

Tribunal de la Inquisición de Murcia, por judaísmo», y en el que, según consta en los datos del catálogo de Blázquez Miguel (1987), ambos fueron condenados a 200 azotes y cárcel perpetua. Cinco ciudadanos de la misma nacionalidad fueron llevados ante el Tribunal en diferentes fechas por el mismo motivo, y con residencia en la capital de la provincia.

Del municipio de Elche hay registrados tres procesos -siglos XVII y XVIII-. En ninguno de ellos tenemos constancia de la sentencia impuesta.

Un acusado de Elda falleció en 1682 durante la celebración del juicio. Se trataba de Francisco Álvarez Franco. Otra ciudadana de origen portugués, Leonor Fernández, aparece con una sentencia suspendida en 1611, estando su residencia situada en Sax (Alicante).

De la población de Orihuela, y a lo largo de los siglos XVII, XVIII, dieciocho fueron los vecinos que terminaron en el Tribunal de la Inquisición de Murcia. Dos de ellos fallecieron durante la celebración del juicio -Francisco Álvarez y Francisco Franco- datado en 1680 para ambos.

$\mathrm{Al}$ igual que hemos reseñado respecto a un juicio de los procedentes de la ciudad de Alicante, también tenemos acceso al expediente del celebrado en 1720 contra el matrimonio formado por Antonio Ruiz de Mendoza y Margarita de Figueroa. ${ }^{19}$ En el contenido de la descripción del sumario se puede leer: «Alegación del proceso de fe de Antonio Ruiz de Mendoza, confitero y su mujer Margarita de Figueroa, originarios de Orihuela, seguido en el Tribunal de la Inquisición de Murcia, por judaísmo».

Sobre los procesos llevados a cabo contra residentes en Orihuela, podemos recurrir a las palabras de Morales y Marín (1977), cuando refiere lo siguiente respecto a los juicios celebrados por el Tribunal de la Inquisición de Murcia durante el siglo XVIII y los casos de interés: «El primero tuvo lugar en los tiempos del Obispo Belluga, el 14 de mayo de 1722, en que fueron condenados a muerte y quemados los judíos Melo y Mary Chaves». ${ }^{20}$ En relación con el apellido Melo, ${ }^{21}$ Blázquez y Miguel (1987) recoge cuatro que coinciden en la misma localidad. El primero, de nombre Fernando, aparece sin sentencia y fue juzgado entre 1692 y 1721 -en un baile de fechas entre la celebración del proceso y el cumplimiento de las sentencias, algo que encontramos en multitud de los juicios extraídos-; por aparecer sin pena señalada, nos decantamos como el posible judío ajusticiado al que se hace referencia en el texto indicado. ${ }^{22}$ También vemos con apellido coincidente a Francisca,

19 http://pares.mcu.es/ParesBusquedas20/catalogo/description/3742701?nm.

20 A pie de página, en la referencia indicada, podemos leer la siguiente nota: «Un manuscrito de la época dice así: "Cuando los conducían al quemadero del otro lado del Puente, cerca de donde están los Molinos, Mary Chaves, volviendo la cabeza y reparando en que unos frailes capuchinos exhortaban a Melo, dijo: 'No te fíes que te engañan'. Recogido por Fuentes y Ponte en 'Fechas Murcianas', 14-5-1722. Murcia, 1882».

21 Del que también podemos aventurarnos sobre su origen portugués aunque no se especifique así.

22 En el catálogo de los procesos inquisitoriales de Blázquez Miguel (1987) encontramos una María Gómez Chaves

SCRIPTA, Revista internacional de literatura i cultura medieval i moderna, núm. 15 / juny 2020 / pp. 175-214 ISSN: 2340-4841 ·doi:/ SCRIPTA.16.19250 
Ramón Doménech Villa. Juicios y sentencias del Tribunal de la Santa Inquisición de Murcia contra ciudadanos residentes en la Corona de Aragón, desde el siglo XV al XIX

Francisco y Mencía Melo, de los es posible consultar su expediente desde el enlace. ${ }^{23}$ Sobre estos acusados en 1720 podemos leer en el apartado correspondiente de la catalogación del archivo digitalizado: «Francisco Melo, cerero y confitero, sus hijas Francisca Melo y Mencía Melo, y su mujer Clara García, originarios de Orihuela, seguido en el Tribunal de la Inquisición de Murcia, por judaizantes». De la mujer e hijas no aparece sentencia ninguna en la relación de Blázquez y Miguel (1987). Del padre, Francisco, se nos señala que fue castigado a 300 azotes y cárcel perpetua, por lo que nos podemos hacer una idea de la gravedad de las acusaciones y de la severidad de la sentencia impuesta.

La relación de juzgados por judaizantes en la ciudad de Villena llama la atención por presentar un número importante de acusados -sobre todo si los comparamos con los del bloque de los islamitas del mismo municipio y con los del resto que presentan una situación similar de compartir la nómina de los dos grupos señalados-, entre los que hay que destacar las doce sentencias de relajación once en estatua- dictadas durante diferentes momentos desde finales del siglo XV -dos de los tres catalogados durante estas fechas- hasta los inicios del XVI. En total, si sumamos los enviados a la cárcel, reconciliados y azotados con cadena perpetua, nos encontramos con quince casos. Debido a la dureza de las condenas, podemos indicar que la mayoría de sentencias de muerte tuvieron lugar entre los años 1502 y 1503. Un vistazo a los nombres y apellidos de los ajusticiados hace que nos fijemos en los tres que llevan por apellido Sánchez Arboleda -Diego, Gonzalo y Luis-, que fueron sentenciados a «relajados en estatua» en 1503.

Para finalizar este apartado podemos señalar los casos de los tres ciudadanos de origen portugués -dos mujeres y un hombre de los que no tenemos sentencia-, con residencia en la ciudad de Valencia y cuyo juicio se celebró en el 1667, a los que hay que añadir el de Juan de Alegría, vecino de la ciudad valenciana de Ayora y juzgado en 1580.

\subsection{Solicitantes y religiosos casados}

Por diversas cuestiones, no pasan desapercibidos los casos relativos a los miembros del clero de diferentes órdenes monásticas que fueron juzgados por solicitar favores sexuales durante el secreto de la confesión y la impartición del sacramento de la penitencia a aquellas personas que se acercaban a ellos. ${ }^{24}$ En el listado podemos observar el gran número de nombres que forman parte de esta relación de encausados, sobre todo en comparación con otros grupos estudiados y teniendo en cuenta la proporción correspondiente. Hay que resaltar que el delito de solicitación podía ser realizado contra

con residencia en Murcia y que fue relajada, según aparece, en el año 1724. También encontramos a una portuguesa de nombre María de Chaves, sin sentencia reflejada, que tuvo su juicio entre 1680 y 1682.

23 http://pares.mcu.es/ParesBusquedas20/catalogo/description/3703802?nm.

24Según lo indicado por Sarrión (2010) «podemos considerar la solicitación toda incitación sexual que el confesor ha hecho al fiel y tiene alguna relación espacio-temporal con el sacramento de la penitencia».

SCRIPTA, Revista internacional de literatura i cultura medieval i moderna, núm. 15 / juny 2020 / pp. 175-214 ISSN: 2340-4841 · doi:/ SCRIPTA.16.19250 
hombres o contra mujeres. De este hecho no existe diferencia en la información del castigo dictaminado recogido por Blázquez Miguel (1987). Lo que parece obvio, y ante sentencias similares relacionadas con la sodomía, es que el hecho de ser cometida la solicitación contra un varón y consumada, sería castigado con una pena todavía más grave que si este delito se hubiera ejercido contra una mujer.

Es cierto que, a simple vista, se puede comprobar cómo las sanciones impuestas adquieren otra dimensión en comparación con las de los grupos anteriores, si bien solo existe testimonio de sentencia en unas pocas de ellas. Pena que normalmente solía ser la abjuración de levi y que se acompañaba de otras sanciones económicas o suspensiones propias de la confianza suscitada por el cargo (administración de los sacramentos, predicación y, por supuesto, la confesión...). No aparece ninguna sentencia absolutoria, a lo sumo la suspensión de la misma, pendiente de otro juicio con más pruebas. El máximo castigo de todos los impuestos, de los incluidos en el catálogo estudiado, fue el que afectó a principios del siglo XVII al mercedario Martín Márquez, procedente de Elche, sancionado con cinco años de destierro.

De la ciudad de Alicante, nueve fueron los clérigos llevados ante el Tribunal. El primero en el año 1613, se trató del franciscano Damián Díaz Navarro, condenado a 4 años de destierro. Después continuaría el goteo de casos hasta llegar al año 1819 con el dominico Domingo Escribá.

Dos son los enjuiciados de este municipio de los que hay constancia en los archivos digitalizados. Por un lado, el del agustino Francisco Pont, ${ }^{25}$ encausado durante el año 1766 «originario de Alicante [...] por solicitante». El segundo, el del franciscano Francisco Pusol, ${ }^{26}$ juzgado en 1788, procedente de la misma ciudad y por el mismo motivo, según aparece en la descripción del archivo correspondiente.

De Ayora y su comarca son once los casos catalogados. Franciscanos ${ }^{27}$ y dominicos, ${ }^{28}$ además del sacerdote Pedro García, llevado al tribunal en 1580, forman parte del listado. Solo nos consta la sentencia de uno de ellos; Marcos Aguilar, que fue reprendido. Sí se ha encontrado digitalizado el caso del franciscano Cristóbal Artigues, ${ }^{29}$ con fecha de juicio de 1750, «originario de Ayora y juzgado por el Tribunal de la Inquisición de Murcia por solicitante».

Sin duda que los municipios con una gran tradición de conventos y parroquias en sus calles son los que más nombres de encausados aportan a la relación de este bloque. Así pasa con la ciudad de Elche, con trece casos justificados. De todos ellos, por existir documentación de los mismos,

25 http://pares.mcu.es/ParesBusquedas20/catalogo/description/3742359?nm.

26 http://pares.mcu.es/ParesBusquedas20/catalogo/show/3739862?nm.

27 En 1573 fue fundado en Ayora por los franciscanos, gracias a la aportación popular, el Convento de San Francisco.

28Según consta en la relación de comunidades por zonas de la Provincia de Hispania de la Orden de los Dominicos (https://www.dominicoshispania.org/), queda comprobada la existencia en el municipio valenciano de una de ellas, existente hasta la exclaustración de 1835, formada por frailes y denominada La Anunciata.

29 http://pares.mcu.es/ParesBusquedas20/catalogo/description/3734592?nm

SCRIPTA, Revista internacional de literatura i cultura medieval i moderna, núm. 15 / juny 2020 / pp. 175-214 ISSN: 2340-4841 · doi:/ SCRIPTA.16.19250 
Ramón Doménech Villa. Juicios y sentencias del Tribunal de la Santa Inquisición de Murcia contra ciudadanos residentes en la Corona de Aragón, desde el siglo XV al XIX

señalamos los de Fray José Navarro y Pacheco $^{30}$ (1729), franciscano «originario de Elche [...] por solicitante»; Fray Manuel Perpiñán (1737), ${ }^{31}$ mercedario que procedía de la misma ciudad que el anterior y fue juzgado por los mismos motivos; Fray Miguel Payá ${ }^{32}(1767)$, dominico en la misma situación que los anteriores; Fray José Martínez ${ }^{33}$ (1786), otro franciscano en idéntico caso; y Francisco Antonio Ferrer ${ }^{34}$ (1806), que ejerció como cura en la ciudad de Elche y fue llevado a los tribunales «por abusos en la administración del sacramento de la penitencia».

Dieciocho juzgados son los que aparecen relacionados con la ciudad de Orihuela, de larga tradición religiosa en diferentes ámbitos -iglesias, conventos, seminarios, colegios...-, además de ser la sede actual de la diócesis correspondiente. A las órdenes religiosas señaladas hasta ahora en la relación de clérigos existentes en este grupo de juzgados, se añaden carmelitas, trinitarios y capuchinos. No poseemos en el censo de Blázquez Miguel (1987) ninguna indicación sobre las sentencias impuestas, si es que se llegó a dictar alguna. Sí podemos señalar tres casos que se pueden consultar en línea, todos ellos pertenecientes al siglo XVIII. Por un lado, el de Mosén Pablo Cerdá, ${ }^{35}$ fechado en 1734 y que engrosa con su presencia la casuística ya reseñada en los anteriormente indicados. También encontramos el del cura de Salvador Puche, ${ }^{36}$ «juzgado en el Tribunal de la Inquisición de Murcia por mala doctrina». Por último, tenemos el del cura de Orihuela, Juan Vicent, ${ }^{37}$ que compartió los motivos con sus compañeros anteriores.

A todos estos enjuiciados hay que añadir otros que se produjeron contra clérigos que realizaban sus labores en diversas poblaciones del Reino de Valencia durante estas fechas. En este sentido, tenemos constancia de 4 de ellos, tres sacerdotes y un franciscano, en Villena; dos en Novelda y Muchamiel; y el resto en localizaciones como Aspe, Biar, Paterna, El Grao, El Valle de la Gallinera, Guardarmar del Segura, Orito, Luchente... Señalar por último, debido a la posibilidad de consultar la información del mismo, el juicio que tuvo lugar en 1713 contra Fray José Gaibiel, ${ }^{38}$ de Monóvar, «por mala conducta».

En la documentación censada resultan curiosos los juicios realizados a religiosos que habían recibido el sacramento del matrimonio. Algo completamente prohibido, como no es necesario explicar. Se

30 http://pares.mcu.es/ParesBusquedas20/catalogo/show/3705060?nm.

31 http://pares.mcu.es/ParesBusquedas20/catalogo/show/3732072?nm.

32 http://pares.mcu.es/ParesBusquedas20/catalogo/show/3738549?nm.

33 http://pares.mcu.es/ParesBusquedas20/catalogo/show/3739702?nm.

34 http://pares.mcu.es/ParesBusquedas20/catalogo/description/3743316?nm.

35 http://pares.mcu.es/ParesBusquedas20/catalogo/show/3706957?nm.

36 http://pares.mcu.es/ParesBusquedas20/catalogo/show/3742394?nm.

37 http://pares.mcu.es/ParesBusquedas20/catalogo/show/3738684?nm.

38 http://pares.mcu.es/ParesBusquedas20/catalogo/show/3741641?nm.

SCRIPTA, Revista internacional de literatura i cultura medieval i moderna, núm. 15 / juny 2020 / pp. 175-214 ISSN: 2340-4841 · doi:/ SCRIPTA.16.19250 
Ramón Doménech Villa. Juicios y sentencias del Tribunal de la Santa Inquisición de Murcia contra ciudadanos residentes en la Corona de Aragón, desde el siglo XV al XIX

constata un caso en cada siglo -XVI, XVII y XVIII- para la zona geográfica y del ámbito del Tribunal que nos interesa, de los quince totales referenciados en Blázquez Miguel (1987). Desglosados estos, señalamos, por orden cronológico, los del Jerónimo Gaspar Botella (1565) condenado a reclusión, sin especificar nada más; Sebastián Aparicio, de la orden de los Agustinos, juzgado en 1642 y sentenciado a pasar 4 años remando en galeras; y el capuchino Manuel Calatayud, con domicilio en Alicante, juzgado en el año 1725 y sin información relativa a la pena impuesta.

\subsection{Bígamos y bígamas}

Numerosa, en proporción, es también la lista de los juicios por bigamia que tuvieron lugar dentro de la demarcación territorial de la Corona de Aragón afectada por las competencias del tribunal murciano. De un total cercano a los trescientos casos de los que hay constancia, cuarenta de ellos pertenecen al ámbito de nuestro interés. Todos ellos fueron juzgados entre los siglos XVI, XVII y XVIII, con diferentes tipos de sentencia, muy duras algunas de ellas. Encontramos, desde los que fallecieron a lo largo de la celebración del juicio, hasta los que recibieron 300 azotes ante la mirada de los espectadores para luego embarcar como galeotes, con el objetivo de completar el castigo impuesto.

Tanto hombres como mujeres aparecen en la relación existente, si bien estas últimas lo están en un número menor. Casos de sentenciadas por bígamas se dieron en la ciudad de Alicante, ${ }^{39}$ como los de Josefa Requena (1678), Josefa Briones (1768) y Manuela Cabrera (1770). A estos hay que añadir los de Ana María Masqueta en Elche (1762), Inés Carneros en Novelda (1742); y los de Catalina Fernández ${ }^{40}$ y Úrsula Vicente ${ }^{41}$ (1563), Isabel Pérez ${ }^{42}$ (1567) y Esperanza López ${ }^{43}(1680)$ que sucedieron en la localidad de Orihuela.

Además de los municipios señalados, existen comprobados casos de juicio por bigamia, cada uno con sus correspondientes sentencias, en Albatera, Callosa de Segura, Cocentaina, Monforte del Cid y Elda.

\subsection{Fornicarios y fornicarias}

Numerosos casos se incluyen dentro del capítulo de aquellos juzgados por cuestiones relacionadas con la moral sexual de la época en la que, paradójicamente como suele suceder, eran los criterios que

39Donde también encontramos que era originario el desterrado a perpetuidad por el mismo motivo, en 1702, Diego Francisco de Vargas.

40 Sacada a la vergüenza, tal y como consta en su sentencia.

41300 azotes le fueron impuestos.

42 Abjura de levi.

43 Condenada a 100 azotes y 4 años de destierro. 
Ramón Doménech Villa. Juicios y sentencias del Tribunal de la Santa Inquisición de Murcia contra ciudadanos residentes en la Corona de Aragón, desde el siglo XV al XIX

surgían del peculiar conocimiento del clero sobre esta cuestión los que marcaban la correspondiente frontera. Estos delitos, considerados como graves, engloban diferentes situaciones y castigos. Algunos dependerán de las características del tribunal y otros del momento de la celebración del juicio.

A los casos de sodomía «clerical», indicados en líneas anteriores en el apartado de los solicitantes -aunque no tenemos constancia manifiesta en ninguno de señalados en la sección-, hay que añadir alguna cuestión relativa a las competencias jurídicas, tal y como indica Kamen (2011). En concreto debemos indicar que, mientras para la Corona de Aragón, Clemente VII en 1524 había declarado competente a la Inquisición para todos los casos que se presentaran con estas características, en la de Castilla solo se juzgaban aquellos que pudieran tener relación con cuestiones relacionadas con la parte herética de los juicios llevados ante el Tribunal.

Por si existía alguna duda, en la relación con las imputaciones que estamos estudiando en este apartado, encontramos juicios celebrados en los tres siglos centrales que forman el núcleo de la actuación del Tribunal de la Inquisición. Alicante, Callosa, Elche, Orihuela, la propia ciudad de Valencia, incluso el pequeño municipio de Granja de Rocamora, en la provincia de Alicante, tienen confirmados juicios contra sus habitantes.

Son varias las situaciones que llaman la atención en la parte de las sentencias. Por un lado la dureza de algunas de ellas. Cien azotes y 2 años de destierro en los casos del ilicitano Pedro Chinchilla, juzgado en 1594, sentencia que coincide en la localidad y en la fecha con la de Alonso de Robles. Doscientos azotes en 1588 con los que fue castigado Jaime Ruiz. Los cien azotes con los que fue sancionada una acusada procedente de Alicante, de nombre María de la Trinidad (1579). Duros también fueron los años de destierro impuestos a Domingo de Aragón (1565), Domingo Hidalgo (1588), Jaime Ripoll (1594) y Bartolomé Olivares (1595).

No pasan desapercibidas aquellas sanciones que fueron derivadas al Tribunal de la Inquisición de Valencia, sin duda, relacionadas con esas competencias sobre determinados casos, señaladas en un párrafo anterior y que diferenciaba las atribuciones según la dependencia a una corona u otra de los correspondientes órganos jurídicos. De los procesos a los que tenemos acceso digital destacaremos dos. El que recoge el juicio en 1777 al sacerdote Francisco Javier López Bueno ${ }^{44}$ por proposiciones, ${ }^{45}$ y que se encuentra entre los remitidos a Valencia. Y el del ciudadano originario de Orihuela Francisco Rocamora, ${ }^{46}$ fechado en 1734, también remitido a Valencia en su momento y cuyo juicio se abrió «por sodomita».

44 http://pares.mcu.es/ParesBusquedas20/catalogo/description/3741849?nm

45 Es posible que debiera estar, si es sacerdote, entre el listado de los solicitantes, pero aquí respetamos lo señalado por Blázquez Miguel, puesto que también llama la atención que fuera enviado al tribunal de Valencia, al contrario que los solicitantes que hemos visto en el apartado correspondiente.

46 http://pares.mcu.es/ParesBusquedas20/catalogo/description/3707807?nm.

SCRIPTA, Revista internacional de literatura i cultura medieval i moderna, núm. 15 / juny 2020 / pp. 175-214 ISSN: 2340-4841 · doi:/ SCRIPTA.16.19250 
Ramón Doménech Villa. Juicios y sentencias del Tribunal de la Santa Inquisición de Murcia contra ciudadanos residentes en la Corona de Aragón, desde el siglo XV al XIX

\subsection{Supersticiosos}

Si en algún momento, y para incluir determinados delitos en los grupos analizados, hemos comprobado la dificultad que existía debido a los límites marcados en cada uno de ellos, en los siguientes que serán analizados esta complejidad aumenta. La subjetividad estará aún más presente en la catalogación, sin duda un proceso difícil para quien ahonda en la tarea de realizar un censo de estas características. Por ese motivo puede despertar mayor interés acudir a los casos particulares, a los que se puede acceder para tener una visión mucho más amplia, siempre que aporten más información para cada uno de ellos. Incluso se puede comprobar cómo confluyen diferentes tipos de delitos en la misma persona y en el mismo juicio.

De los cerca de trecientos casos que aparecen relacionados por asuntos de superstición, setenta y nueve son de nuestro ámbito de interés. Pero no es solo el importante número de aquellos que fueron llevados ante el Tribunal por múltiples prácticas que deben estar incluidas en esta relación, llama mucho más la atención el número de mujeres que fueron juzgadas por la causa general indicada. En esta ocasión superan ampliamente la mitad de los señalados. Muchas de ellas sufrieron las penas de azotes y destierro, a las que hay que sumar un importante número de reprendidas.

Además de las principales poblaciones ya señaladas en más de una ocasión -Alicante, Orihuela, Elche, Novelda, Callosa, Ayora, Elda...-, es llamativo un caso contra un ciudadano de Gandía, Vicente Agramonte, con fecha de 1615, y que fue reprendido, así como el realizado contra un ciudadano de la isla de Tabarca en 1640, Alonso Sánchez, y del que no nos consta sentencia.

Los juicios a los que tenemos acceso vía archivo digital, por motivos obvios, son también más numerosos que en otras secciones; si bien todos están catalogados en el siglo XVIII. Empezaremos por el de la ciudadana con residencia en Villena, ${ }^{47}$ Juana Arnau, ${ }^{48}$ realizado en 1732, y cuyo asunto fue llevado al Tribunal de la Inquisición por «embustera y supersticiosa». Un año después, $1733,{ }^{49}$ encontramos los datos del juicio contra Juan Sala, ${ }^{50}$ originario de Novelda, por «supersticioso y sortílego». Manuel Hervás, ${ }^{51}$ «escribano de la renta del tabaco, originario de Orihuela», fue culpado en 1734 por «supersticiones». Al año siguiente sería otro vecino de la misma población, en concreto José Marco, ${ }^{52}$ el procesado por «sortílego». Del cercano municipio al anterior, de Callosa de Segura, era Antonia Dabo, quien acabó en el Tribunal de la Inquisición de Murcia en 1753 por ser «fingidora

47 En el apartado «alcance y contenido» del archivo digitalizado se indica que es ciudadana de Murcia pero Blázquez Miguel (1987) la señala como procedente de la ciudad alicantina de Villena.

48 http://pares.mcu.es/ParesBusquedas20/catalogo/show/3706012?nm.

491739 si vamos a la fecha de formación señalada en la identificación del archivo digitalizado.

50 http://pares.mcu.es/ParesBusquedas20/catalogo/show/3732967.

51 http://pares.mcu.es/ParesBusquedas20/catalogo/show/3707564?nm.

52 http://pares.mcu.es/ParesBusquedas20/catalogo/show/3705901?nm.

SCRIPTA, Revista internacional de literatura i cultura medieval i moderna, núm. 15 / juny 2020 / pp. 175-214 ISSN: 2340-4841 · doi:/ SCRIPTA.16.19250 
Ramón Doménech Villa. Juicios y sentencias del Tribunal de la Santa Inquisición de Murcia contra ciudadanos residentes en la Corona de Aragón, desde el siglo XV al XIX

de revelaciones». «Por supersticiones» también fue castigado en 1757 el ilicitano Diego Embid. ${ }^{53}$ En la primera mitad del siglo XVIII fueron llevados a juicio por motivos parecidos dos ciudadanos con residencia en Alicante, aunque cada uno por cuestiones diferentes. Por un lado, Diego Martínez, ${ }^{54}$ su caso terminó en el Tribunal de Murcia al ser un «supersticioso y blasfemo». A este se le añadió el de Luis de Mon - de fecha más dudosa que el anterior, aunque en la misma categoría de los que estamos viendo-, que no puede pasar desapercibido por dos motivos, ya que era «natural de Francia, soldado preso en el baluarte de Alicante» y hasta el tribunal le llevaron «por supersticiones y pacto explícito con el demonio».

\subsection{Blasfemos}

Como hemos podido comprobar en la sección anterior, las fronteras entre unos y otros delitos a veces eran difíciles de limitar. Incluso algunos de los ciudadanos enjuiciados aparecen con distintas acusaciones, estableciéndose una estrecha, y a veces compleja, relación en el límite entre cada uno de ellos. Tal era el caso de los acusados por blasfemia que vamos a ver en este apartado con cuarenta y dos juzgados durante los siglos XVI, XVII y XVIII procedentes de territorios de la Corona de Aragón.

Algunos de los temas señalados nos son ya conocidos, como es el caso de las diferentes sentencias dictadas y la distinta dureza de las mismas. Una visión general de ellas nos indica que los azotes y el destierro eran decisiones comunes para la gran mayoría de los cuarenta y dos casos filtrados. En este sentido, podemos destacar los cien azotes impuestos en 1568 al ciudadano francés residente en Cox (Alicante), Penigasque Gentiles. También de origen francés con residencia en la ciudad de Alicante era Juan Berceba (1635), al que se le impusieron diez años de destierro. Una pena, la del destierro, que para los acusados de blasfemia podía ir acompañada de los correspondientes centenares de azotes propinados. De esta manera, tenemos los cien azotes y cinco años de destierro impuestos al ilicitano Francisco de Perpiñán ${ }^{55}$ en el año 1565; o los 200 azotes y cuatro años como galeote con los que se castigó la actitud del residente en el municipio alicantino de Castalla en el año 1621, Domingo Sierra. Más por su profesión, la de sacerdote, que por la pena impuesta (el juicio fue suspendido), merece mención Antón Doménech, residente en Villena y juzgado durante el año 1664. Si seguimos el listado observaremos que, a diferencia del bloque anterior, la presencia femenina es inexistente. Solo un caso se presenta novedoso, y es la excepción a lo dicho en la línea anterior; el de una «prostituta» juzgada y procedente de la ciudad de Elche en 1611, de la que carecemos sus datos personales y únicamente consta a lo que se dedicaba.

De los nueve procesos contra individuos procedentes de la ciudad de Alicante, podemos acceder

53 http://pares.mcu.es/ParesBusquedas20/catalogo/show/3735445?nm.

54http://pares.mcu.es/ParesBusquedas20/catalogo/show/3741906?nm.

55 Un apellido que también nos hace sospechar el posible origen del juzgado.

SCRIPTA, Revista internacional de literatura i cultura medieval i moderna, núm. 15 / juny 2020 / pp. 175-214

ISSN: 2340-4841 · doi:/ SCRIPTA.16.19250 
Ramón Doménech Villa. Juicios y sentencias del Tribunal de la Santa Inquisición de Murcia contra ciudadanos residentes en la Corona de Aragón, desde el siglo XV al XIX

a los siguientes expedientes digitalizados. En primer lugar, señalaremos el que tuvo como acusado a Diego Martínez ${ }^{56}$ en 1745. Martínez, que según lo señalado era «sastre y originario de Alicante», y fue llevado a juicio por «supersticioso y blasfemo». Por blasfemias, según consta, también fue juzgado en 1758 «el marinero preso en Alicante», Luis Berenguer. ${ }^{57}$ Cuatro años más tarde, 1762, por el mismo motivo sería llevado al Tribunal «el desertor, preso en la cárcel Real de Alicante», José Fuentes.

De la ciudad de Almoradí, de los dos sumarios que hay reseñados, procedía Ramón Gill. ${ }^{58}$ En este caso, tal y como señala la descripción del archivo, se trataba de un individuo que se encontraba «preso» en ese municipio, y cuyo delito fue haber pronunciado «blasfemias hereticales».

Blázquez Miguel (1987) incluye en esta sección a un eldense de nombre Francisco Barberá. El mismo nombre y las mismas fechas de juicio (1777) aparecen en el apartado del catálogo dedicado a las «proposiciones». ${ }^{59}$ Este Barberá se señala en la sección «alcance y contenido» del archivo digitalizado como procedente de la localidad de Salinas, junto al motivo del juicio. Sea de una forma o de otra, lo incluimos en esta sección por entenderlo relevante para este trabajo.

«Teniente Alguacil» del municipio de Orihuela era José Duque ${ }^{60}$ cuando fue juzgado en la ciudad de Murcia en el año 1736 por «blasfemias y hechos heréticos». Del mismo municipio, por nacimiento o por residir en él durante su detención, eran los encausados Miguel Escribá, ${ }^{61}$ llevado a juicio en 1738, «blasfemo preso en la cárcel de Orihuela»; y Antón Aliaga, ${ }^{62}$ juzgado en 1767, «tejedor de lienzos, originario de Orihuela, juzgado en el Tribunal de la Inquisición de Murcia, por blasfemias».

\subsection{Sacrílegos e irreverentes}

Destierros, multas con diversas cantidades y azotes, entre otros, eran los castigos que esperaban a los acusados de estos dos grupos, que se unen a los que forman parte de los delitos separados por esa extraña limitación a la que ya hemos hecho referencia. Unos listados no muy extensos en los que llama la atención la presencia de la esclava Aljamora, procedente de Elche, juzgada por sacrílega en el 1625, y condenada a unos horrorosos doscientos azotes.

56 http://pares.mcu.es/ParesBusquedas20/catalogo/show/373956.

57 http://pares.mcu.es/ParesBusquedas20/catalogo/show/3735415

58 http://pares.mcu.es/ParesBusquedas20/catalogo/show/3739561.

59 En el mismo bloque se nos indica que su origen era San Miguel de Salinas, que no dista mucho de Elda, nueva localización, y que se encontraría también en la zona de competencias del Tribunal.

60 http://pares.mcu.es/ParesBusquedas20/catalogo/show/3723686.

61 http://pares.mcu.es/ParesBusquedas20/catalogo/show/3741526.

62 http://pares.mcu.es/ParesBusquedas20/catalogo/show/3738106.

SCRIPTA, Revista internacional de literatura i cultura medieval i moderna, núm. 15 / juny 2020 / pp. 175-214 ISSN: 2340-4841 · doi:/ SCRIPTA.16.19250 
Ramón Doménech Villa. Juicios y sentencias del Tribunal de la Santa Inquisición de Murcia contra ciudadanos residentes en la Corona de Aragón, desde el siglo XV al XIX

Sin duda, debemos destacar el juicio masivo que tuvo lugar en el siglo XVIII. En él fueron llevados ante el Tribunal de la Inquisición de Murcia los «originarios de Crevillente», José Quesada, José Galipienzo y Francisco Gallardo. ${ }^{63}$ El delito, según consta: «hecho sacrílego».

En el grupo de los juzgados por irreverentes, un breve listado de tres dentro de la zona geográfica de nuestro interés, donde resultan llamativos una serie de datos. Por un lado, el juicio contra el esclavo de Novelda, Diego Hernández, en 1570, cuya sentencia, según nos señala Bázquez Miguel (1987), fue la de ser «ser sacado a la vergüenza». Por otro, tal vez uno de los juicios más tardíos realizados, el del oriolano Manuel Alonso, llevado ante el Tribunal en el año 1819.

\subsection{Delitos contra el Santo Oficio}

Dentro de la amplia relación de delitos que se podían cometer también existe una relación de aquellos que se producían directamente contra el Santo Oficio - presentes y juzgados durante más de tres siglos-. Los condenados se enfrentaban a severas multas económicas, penas de destierro o ser reprendidos a raíz de la correspondiente sentencia.

José Santa María, ${ }^{64}$ oriolano, fue también, por cuestión de fechas (1815) de aquellos que formaron parte del listado de condenados de los últimos años de vigencia del Tribunal. Sin duda, la descripción de su acusación es de lo más significativo, sobre todo si tenemos en cuenta las fechas a las que nos estamos refiriendo y las consecuencias posteriores que conocemos: «por retener y hacer uso del manifiesto de las Cortes sobre extinción de la Inquisición».

\subsection{Delitos varios y desconocidos}

Aunque muy breve, sin duda es uno de los listados más curiosos dentro de los diferentes catalogados; es llamativa la descripción de los delitos cometidos por aquellos que forman parte de la correspondiente relación. Nos estamos refiriendo a los de los enjuiciamientos que no comparten ninguna de las clasificaciones anteriores, pero que fueron llevados ante el Tribunal de la Inquisición para que dictara la correspondiente sentencia o absolución. Por su brevedad, es posible resumir la relación cronológica de cada uno de ellos.

Por un lado, tenemos en 1631 el juicio al ciudadano de origen portugués Pedro Juárez de Ribera, procedente de Alicante y que fue perdonado por los enjuiciadores, acusado de querer «pasar a Francia sin licencia». Más curioso fue el caso del oriolano Tomás Martínez, quien en 1707 fue condenado a la pena de «6 años de destierro» por el hecho de «escribir un libro». Procedente

63 http://pares.mcu.es/ParesBusquedas20/catalogo/show/3742439.

64 http://pares.mcu.es/ParesBusquedas20/catalogo/show/3743527.

SCRIPTA, Revista internacional de literatura i cultura medieval i moderna, núm. 15 / juny 2020 / pp. 175-214 ISSN: 2340-4841 · doi:/ SCRIPTA.16.19250 
Ramón Doménech Villa. Juicios y sentencias del Tribunal de la Santa Inquisición de Murcia contra ciudadanos residentes en la Corona de Aragón, desde el siglo XV al XIX

de Elda era el franciscano Urbano Moltó, juzgado por «exhortar a la rebelión» en 1709. Tomás Cerdá, fue juzgado en 1762 por «hechos heréticos». ${ }^{65}$ Por último, en 1816, al vecino de Muchamiel Laureano Antón se le acusó de «desacato a la iglesia».

De la relación de casos conservados y que se desconoce el delito de los mismos, es difícil destacar alguno de ellos, justo por este motivo de imprecisión. Como es lógico, la nómina se extiende a lo largo de los años en los que la Inquisición impuso su particular justicia, y de ella también forman parte ciudadanos extranjeros, mujeres y otros procedentes del estamento clerical, como se refleja en la figura de dos sacerdotes que fueron llevados ante el Tribunal

\section{Conclusiones}

Tras el estudio de las diferentes causas que han formado parte del trabajo, podemos realizar una serie de afirmaciones, que nos permitirán establecer nuevas pautas de investigación y proponer nuevas propuestas de ampliación sobre algunos de los resultados obtenidos.

Por un lado, observamos que, por motivos de competencias de ámbito religioso y por su cercanía y atribuciones sobre la Diócesis de Orihuela-Alicante -creada definitivamente en 1564 tras varios intentos anteriores y diferentes trifulcas-, el Tribunal Permanente de la Inquisición con sede en la ciudad de Murcia -situado en el territorio histórico de la Corona de Castilla- ejerció sus funciones, entre otros, durante toda su vigencia, sobre determinados territorios pertenecientes a la Corona de Aragón y, más en concreto, al Reino de Valencia. A estos podemos añadirle los municipios que forman la actual provincia de Albacete, por cuestiones jurisdiccionales desde el siglo XIII al formar parte del antiguo Reino de Murcia, y de las localidades de Sax y Villena -pertenecientes al ámbito territorial murciano e incorporadas a la provincia de Alicante a partir de 1833 tras la reforma de administrativa de Javier de Burgos, así como lo dictado por otras Reales Órdenes posteriores- (Vilar 2004).

Por otra parte, podemos confirmar que la proporción de juicios llevados a cabo por el Tribunal durante sus más de tres siglos de vigencia, ${ }^{66}$ contra los ciudadanos procedentes de la zona geográfica de competencias señalada, se mantiene de igual manera en cada uno de los diferentes grupos creados en el catálogo publicado por Blázquez Miguel (1987) -y que ha servido de base para este trabajo-, respecto al resto de originarios procedentes de municipios de la Corona de Castilla, sobre los que este Tribunal tenía asignadas sus competencias de actuación. Este equilibrio de inculpados se mantiene en relación con otros aspectos que han sido analizados en párrafos anteriores: hombres, mujeres, sentencias ejecutadas, absoluciones... En este sentido, podemos añadir que respecto a algunos de

65 Alguno de estos casos estaban en el grupo de «blasfemos» pero Blázquez Miguel (1987) incluye este caso aquí, y por eso se respeta esta decisión.

66 Desde 1478 hasta 1834, como ya se ha señalado en más de una ocasión.

SCRIPTA, Revista internacional de literatura i cultura medieval i moderna, núm. 15 / juny 2020 / pp. 175-214 ISSN: 2340-4841 · doi:/ SCRIPTA.16.19250 
los enjuiciados a los que se les asigna origen en una localidad determinada, se ha podido comprobar que se trataba de encarcelados que cumplían sentencia en un penal de ese lugar, por la misma o por diferentes causas a la incoada, con un gran número perteneciente a distintas nacionalidades.

El análisis realizado, con la pertinente agrupación local como primer criterio para realizar los respectivos análisis, nos ha permitido confirmar la existencia de diferentes puntos de encuentro que han sido reflejados en cada una de las secciones: fechas, localidades afectadas, sentencias, juicios colectivos... Todos ellos se pueden comprobar con la lectura de las distintas categorías y con los datos que aparecen en las tablas incluidas en el anexo correspondiente, que han sido ordenados cronológicamente, permitiéndonos establecer las conclusiones que ya han sido manifestadas en cada una de las secciones afectadas.

Sin bien se pueden constatar la existencia de algunos datos confusos en el catálogo de Blázquez Miguel (1987) -referentes a nombres, apellidos, localidades o grupo estadístico de acusaciones-, algo normal debido a la dificultad encontrada a la hora de realizar el trabajo de campo y catalogación correspondiente, junto al volumen de documentación consultada, el magnífico resultado del mismo se ha convertido en la base fundamental para el presente artículo. Un trabajo que se ha ampliado, dentro de los subgrupos que presentamos, con el acceso a aquellos expedientes juzgados por el Tribunal que afectan a este estudio, y que se encuentran en formato digital, ${ }^{67}$ una cuestión que nos ha permitido ampliar la información relativa de cada uno de ellos: origen, trabajo desempeñado, relaciones de parentesco...

La facilidad para acceder a la documentación de estos juicios digitalizados, junto a la comprobación de que muchos de ellos no tienen sentencia reflejada en el catálogo de Blázquez Miguel (1987), nos lleva a la propuesta de ampliación de aquellos referenciados y que deberían ser estudiados de forma más detallada para ampliar la información correspondiente a los veredictos dictados, algo que ayudaría a completar y confirmar la información relativa a estos aspectos en el censo señalado y sumar el resto de grupos afectados.

67 http://pares.mcu.es/ParesBusquedas20/catalogo/autoridad/44351 
Ramón Doménech Villa. Juicios y sentencias del Tribunal de la Santa Inquisición de Murcia contra ciudadanos residentes en la Corona de Aragón, desde el siglo XV al XIX

\section{Bibliografía}

Blázquez Miguel, Juan (1987) «Catálogo de los procesos inquisitoriales del Tribunal del Santo Oficio de Murcia» En Academia Alfonso X el Sabio (ed.), Revista Murgetana, 74, pp. 6-109.

Carpio Valero, Vicente; Sainz Martín, Amalia; Teruel Alamán, Arturo; López Ferri, Pedro; Rafael Piera, Rafael (1999). Ayora, nuestra bistoria un paseo por nuestro pasado. Ayuntamiento de Ayora, Ayora.

Kamen, Henry (2011 [1 $1^{\mathrm{a}}$ ed. 1999]). La Inquisición Española. Una revisión histórica. Barcelona, Crítica.

Martín Hernández, Francisco (1980). «La Inquisición en España antes de los Reyes Católicos». En Joaquín Pérez Villanueva (ed.) La Inquisición española. Nueva visión, nuevos horizontes. Madrid, Siglo XXI, pp. 11-28.

Morales y Marín, José Luis (1977). «El Alcázar de la Inquisición en Murcia». En Academia Alfonso X el Sabio (ed.), Revista Murgetana, 46, pp. 39-91.

Pérez, Joseph (2012 [1ª ed. 2009]. Breve Historia de la Inquisición en España. Barcelona, Crítica.

Sarrión Mora, Adelina (2010). Sexualidady confesión: la solicitación ante el Tribunal del Santo Oficio (siglos XVI-XIX). Madrid, Alianza Editorial.

Vilar Ramírez, Juan Bautista (2004). «El proceso de vertebración territorial de la Comunidad de Murcia: de reino histórico a autonomía uniprovincial». Revista de Estudios Regionales, 69, pp. $245-$ 247. 
Ramón Doménech Villa. Juicios y sentencias del Tribunal de la Santa Inquisición de Murcia contra ciudadanos residentes en la Corona de Aragón, desde el siglo XV al XIX

\section{RELACIÓN DE SIGLAS Y ABREVIATURAS ${ }^{68}$}

\section{NACIONALIDADES}
(b) Berberisco
(it) Italiano
(f) Francés
(p) Portugués

\section{RELIGIOSOS}

(JER) Jerónimo

(OC) Carmelita

(OFM) Franciscano

(OFM Cap) Capuchino

$(\mathrm{OM})$ Mercedario

(OP) Dominico

(OSA) Agustino

(OSST) Trinitario

(S) Sacerdote

(OV) Orden de la Victoria

68 Según lo indicado por Blázquez Miguel (1987) y que afectan a la selección de juicios realizada para este artículo.

SCRIPTA, Revista internacional de literatura i cultura medieval i moderna, núm. 15 / juny 2020 / pp. $175-214$ ISSN: 2340-4841 · doi:/ SCRIPTA.16.19250 
Ramón Doménech Villa. Juicios y sentencias del Tribunal de la Santa Inquisición de Murcia contra ciudadanos residentes en la Corona de Aragón, desde el siglo XV al XIX

\section{Anexos: Relación cronológica de Procesos Inquisitoriales del Tribunal del Santo Oficio de Murcia contra ciudadanos de la Corona de Aragón (Siglos XVI, XVII, XVIII y XIX)}

\section{ISLAMITAS}

\begin{tabular}{|c|c|c|c|}
\hline APELLIDO Y NOMBRE & LOCALIDAD & $A \tilde{N} O$ & SENTENCIA \\
\hline BARATO, Isabel & CREVILLENTE (A) & 1554 & Reconciliada \\
\hline PÉREZ, José & VALENCIA & 1563 & 500 azotes y galeras a perpetuidad \\
\hline Juan Adrián & ASPE (A) & 1564 & $\begin{array}{c}100 \text { azotes, un mes de } \\
\text { cárcel y multa de } 50 \\
\text { ducados }\end{array}$ \\
\hline XARQUE, Juan de & CREVILLENTE (A) & 1565 & Un año de reclusión \\
\hline CASQUE, Isabel & ALICANTE & 1566 & - \\
\hline ALFAFAR, Rodrigo & ASPE (A) & 1566 & - \\
\hline ALPEJO, Baltasar & ASPE (A) & 1566 & - \\
\hline BERNABIL, Pedro & ASPE (A) & 1566 & - \\
\hline LUGO, Miguel & ASPE (A) & 1566 & - \\
\hline BAYAZÁN, Gaspar & ELCHE (A) & 1566 & - \\
\hline HAMZ, Beatriz & ASPE (A) & 1567 & 2 meses de cárcel \\
\hline ALPES, Baltasar & ASPE (A) & 1567 & $\begin{array}{l}2 \text { meses de cárcel y } \\
\text { multa de } 6000 \text { maravedíes }\end{array}$ \\
\hline LEGO PUJOL, Miguel & ASPE (A) & 1567 & $\begin{array}{l}2 \text { meses de cárcel y multa } \\
\text { de } 6000 \text { maravedies (mrs.) }\end{array}$ \\
\hline BERNABIL, Pedro & ASPE (A) & 1567 & $\begin{array}{l}\text { Un año de cárcel y } \\
\text { multa de } 6000 \text { mrs. }\end{array}$ \\
\hline ALMILA, Luis & ASPE (A) & 1568 & - \\
\hline ALPES, Luisa & ASPE (A) & 1568 & 2 meses de cárcel \\
\hline MALÓN, Gaspar & ELCHE (A) & 1568 & 3 meses de cárcel \\
\hline NIMOYO, Nofrefaro & ELDA (A) & 1568 & 6 años en galeras \\
\hline AMAR, Beatriz & ASPE (A) & 1568 & 6 meses de cárcel \\
\hline MORÓN, Catalina & $\operatorname{ASPE}(\mathrm{A})$ & 1568 & 6 meses de cárcel \\
\hline MOLÓN, Miguel & ELCHE (A) & 1568 & 6 meses de cárcel \\
\hline PELLICER, Pedro & ELCHE (A) & 1568 & Cárcel \\
\hline FAJAR, Rodrigo de & ASPE (A) & 1568 & Relajado \\
\hline MANDADO, José & ASPE (A) & 1568 & Relajado \\
\hline MARTÍNEZ, Francisco & ASPE (A) & 1568 & Relajado \\
\hline FERNÚN, Ginés & ELCHE (A) & 1568 & Un año de cárcel \\
\hline PERICÓN, Juan & ELCHE (A) & 1568 & Un año de cárcel \\
\hline ADURAZAT, Ginés & ASPE (A) & 1570 & - \\
\hline BERMEJO, viuda de & ASPE (A) & 1570 & - \\
\hline PEPEU, Miguel & CHIVA (V) & 1570 & - \\
\hline AFIF, Francisco & $\begin{array}{l}\text { LA GRANJA DE ROCAMORA } \\
\text { (A) }\end{array}$ & 1570 & Destierro perpetuo \\
\hline ALBIÁN, Diego & ASPE (A) & 1570 & \\
\hline XAQUIN, Francés & $\operatorname{ASPE}(\mathrm{A})$ & 1571 & - \\
\hline CARLES, Luis & ASPE (A) & 1571 & 6 meses de reclusión \\
\hline XEUXEU, Miguel & CHIVA (V) & 1571 & Relajado \\
\hline BENACHIL, Nofre & NOVELDA (A) & 1572 & $\begin{array}{c}200 \text { azotes y } 10 \text { años } \\
\text { en galeras }\end{array}$ \\
\hline ARBI, Francés & VALENCIA & 1572 & $\begin{array}{c}200 \text { azotes y } 10 \text { años } \\
\text { en galeras }\end{array}$ \\
\hline JUMILLA, Juan & ELCHE (A) & 1572 & 4 años de cárcel \\
\hline ADAL, Gaspar & BUÑOL (V) & 1573 & - \\
\hline BONAZ, Baltasar & NOVELDA (A) & 1573 & $\begin{array}{c}200 \text { azotes y destierro } \\
\text { perpetuo }\end{array}$ \\
\hline MAS, Francisco & ELDA (A) & 1573 & Abjura de levi \\
\hline PAAMUD, Leonor & ASPE (A) & 1573 & \\
\hline Elena & CREVILLENTE (A) & 1575 & Absuelta \\
\hline
\end{tabular}


Ramón Doménech Villa. Juicios y sentencias del Tribunal de la Santa Inquisición de Murcia contra ciudadanos residentes en la Corona de Aragón, desde el siglo XV al XIX

\begin{tabular}{|c|c|c|c|}
\hline PELILLO, Francés & CREVILLENTE (A) & 1577 & 100 azotes y 3 años de cárcel \\
\hline ALHEYLA, Juan & CREVILLENTE (A) & 1577 & 3 años de cárcel \\
\hline CAIMÓN, Juan & ELCHE (A) & 1577 & 3 años de cárcel \\
\hline ZAMBAROT, Francés & CREVILLENTE (A) & 1577 & Absuelto \\
\hline VACA, Pedro & NOVELDA (A) & 1577 & Cárcel \\
\hline VARÓN, Martín & $\operatorname{ELDA}(\mathrm{A})$ & 1579 & Un año de cárcel \\
\hline Caitón & AYORA (V) & 1580 & - \\
\hline CORTEJA, Francisco & AYORA (V) & 1580 & - \\
\hline Hubenn & AYORA (V) & 1580 & - \\
\hline Humeite & AYORA (V) & 1580 & - \\
\hline Munjor & AYORA (V) & 1580 & - \\
\hline Zumeize & AYORA (V) & 1580 & - \\
\hline ZARCÓTE, Ángela & ASPE (A) & 1580 & 6 meses de cárcel \\
\hline CANONGE, Gaspar & ELDA (A) & 1580 & Abjura de levi \\
\hline ZACARÍA, Jaime & ELCHE (A) & 1580 & Abjura de vehementi \\
\hline MAGÁN, Ángela & ELDA (A) & 1580 & Abjura de vehementi \\
\hline Esperanza & NOVELDA (A) & 1581 & - \\
\hline PEDRAZA, Pedro & MONÓVAR (A) & 1581 & 100 azotes \\
\hline Francés Ramón & ELDA (A) & 1581 & Reprendido \\
\hline CANSATE, Jerónimo & POLOP (A) & 1582 & Abjura de vehementi \\
\hline MACÁN, Melchor & ASPE (A) & 1582 & Absuelto \\
\hline TESTAREE, Francés & TABERNES $(\mathrm{V})$ & 1582 & Absuelto \\
\hline ALULAYA, Francisco & ORIHUELA (A) & 1582 & Multa de 50 ducados \\
\hline BERNIZO, Francisco & ELDA (A) & 1584 & Absuelto \\
\hline NAVARRO, Juan Bautista & VALENCIA & 1584 & Absuelto \\
\hline AZCAR, Rodrigo & CREVILLENTE (A) & 1584 & Relajado \\
\hline CAZAL, Antón & ELDA $(\mathrm{A})$ & 1584 & Relajado \\
\hline CATALÁN, Juan & VALENCIA & 1584 & Relajado \\
\hline ZANDINY, Juan & ELCHE (A) & 1585 & 200 azotes y multa de $2000 \mathrm{mrs}$. \\
\hline MANDARANA, María & CREVILLENTE (A) & 1585 & 6 meses de cárcel \\
\hline TORO, Lucas de & IBIZA (IB) & 1585 & Absuelto \\
\hline BABAC, Francisco & JALÓN (A) & 1585 & Absuelto \\
\hline SARRIÁ, Pau & $\operatorname{ELDA}(\mathrm{A})$ & 1585 & Suspendida \\
\hline ALBADY, Juan & CREVILLENTE (A) & 1585 & Un año de reclusión \\
\hline FARACH, Leonor & ELCHE (A) & 1586 & - \\
\hline SERRANO, Diego & ALBATERA (A) & 1586 & 100 azotes y 4 años en galeras \\
\hline ARBI, Gaspar & JALÓN (A) & 1586 & $\begin{array}{l}100 \text { azotes y } 6 \text { años } \\
\text { en galeras }\end{array}$ \\
\hline BAL, Miguel & POLOP (A) & 1586 & $\begin{array}{l}100 \text { azotes y } 6 \text { años } \\
\text { en galeras }\end{array}$ \\
\hline MARCO, Juan & ALBATERA (A) & 1586 & 100 azotes y reclusión \\
\hline HERNÁNDEZ, Isabel & ALBATERA (A) & 1586 & $\begin{array}{c}100 \text { azotes y un año de } \\
\text { destierro }\end{array}$ \\
\hline PUZEY, Damián & ELDA (A) & 1586 & 200 azotes y 6 años en galeras \\
\hline BERNIZO, Alonso & ELDA (A) & 1586 & 3 años en galeras \\
\hline BELVIS, María & $\operatorname{ASPE}(\mathrm{A})$ & 1586 & 4 años de cárcel \\
\hline UBACAR, Juan & $\operatorname{ELDA}(\mathrm{A})$ & 1586 & 4 años en galeras \\
\hline BELVIS, Bartolomé & $\operatorname{COX}(\mathrm{A})$ & 1586 & 5 años de cárcel \\
\hline MEJIJO, Enrique & ALBATERA (A) & 1586 & 5 años en galeras \\
\hline BELVIS, Diego & $\operatorname{COX}(\mathrm{A})$ & 1586 & 5 años en galeras \\
\hline BOLUYAS, Guillén de & BOLULLA (A) & 1586 & 6 años en galeras \\
\hline PAXIS, Miguel & POLOP (A) & 1586 & 6 años en galeras \\
\hline BENTALFA, Pedro & $\operatorname{ELDA}(\mathrm{A})$ & 1586 & Absuelto \\
\hline
\end{tabular}


Ramón Doménech Villa. Juicios y sentencias del Tribunal de la Santa Inquisición de Murcia contra ciudadanos residentes en la Corona de Aragón, desde el siglo XV al XIX

\begin{tabular}{|c|c|c|c|}
\hline SALA, Rodrigo & ELCHE (A) & 1586 & Relajado \\
\hline MAXATO, Francisco & $\operatorname{ELDA}(\mathrm{A})$ & 1586 & Relajado \\
\hline María & ALBATERA (A) & 1586 & Un año de destierro \\
\hline APARICIO, Leonor & ELCHE (A) & 1587 & Abjura de levi \\
\hline MAHAMUX, Juan & $\operatorname{ASPE}(\mathrm{A})$ & 1587 & Absuel to \\
\hline JUAN, esclavo & IBIZA (IB) & 1587 & Falleció \\
\hline BARVEZ, Cosme & CALLOSA DE ENSARRIÁ (A) & 1587 & Galeras a perpetuidad \\
\hline Duayma & AYORA $(\mathrm{V})$ & 1588 & - \\
\hline Francisco, esclavo & ALICANTE & 1588 & 100 azotes \\
\hline Francisco, esclavo & ALICANTE & 1588 & 100 azotes \\
\hline Juan, esclavo & ALICANTE & 1588 & 200 azotes \\
\hline RULET, Juan & ELCHE (A) & 1588 & 4 años en galeras \\
\hline PÉREZ, Antón & $\begin{array}{l}\text { LA GRANJA DE ROCAMORA } \\
(\mathrm{A})\end{array}$ & 1588 & 6 años en galeras \\
\hline COCUMA, Martín & PETREL $(\mathrm{A})$ & 1588 & 6 años en galeras \\
\hline Francisco, esclavo & ALICANTE & 1588 & Abjura de levi \\
\hline Diego, esclavo & ALICANTE & 1588 & Abjura de vehementi \\
\hline Juan, esclavo & ALICANTE & 1588 & Absuelto \\
\hline GÓMEZ, Gil & ASPE (A) & 1588 & Un año de cárcel \\
\hline MANAR, Juan & MONÓVAR (A) & 1592 & $\begin{array}{c}200 \text { azotes y } 2 \text { años de } \\
\text { destierro }\end{array}$ \\
\hline ROCHE, Francés & ALBATERA (A) & 1592 & 200 azotes y 4 años de cárcel \\
\hline BAYDA, Luis & ALBATERA (A) & 1592 & 4 años en galeras \\
\hline Francisco (b) & ELDA (A) & 1592 & Absuelto \\
\hline ZARAGOZA, Martín & $\operatorname{ELDA}(\mathrm{A})$ & 1592 & Absuelto \\
\hline ALAZÓN, Francisco & ASPE (A) & 1592 & Galeras \\
\hline MAYO, María & ASPE (A) & 1593 & - \\
\hline ALACAYO, Juan & ASPE (A) & 1594 & 100 azotes y cárcel perpetua \\
\hline ZUZENA, María & NOVELDA (A) & 1594 & 3 años de cárcel \\
\hline DUBDU, Luis & ALBATERA (A) & 1594 & 5 años en galeras \\
\hline ALCOREAN, Alonso & ASPE (A) & 1594 & 5 años en galeras \\
\hline BENTALJOHA, Juan & $\operatorname{ELDA}(\mathrm{A})$ & 1594 & 5 años en galeras \\
\hline RUTA, Luis & ASPE (A) & 1594 & 6 años en galeras \\
\hline PEPI, Bartolomé & NOVELDA (A) & 1594 & 8 años en galeras \\
\hline DURRAMEN, Hernando & ASPE (A) & 1594 & Absuelto \\
\hline FAJARDO, Lorenzo & $\operatorname{ASPE}(\mathrm{A})$ & 1594 & Absuelto \\
\hline VENTALFA, Martín & ELDA (A) & 1594 & Absuelto \\
\hline Lorenzo & NOVELDA (A) & 1594 & Absuelto \\
\hline ZUZENA, Isabel & NOVELDA (A) & 1594 & Cárcel perpetua \\
\hline TORREGROSA, Miguel de & ALICANTE & 1594 & Reconciliado \\
\hline MATA, Pedro Antonio & MALLORCA (IB) & 1594 & Reconciliado \\
\hline MAJAROTE, Beatriz & PETREL (A) & 1594 & Suspendida \\
\hline MAXOROTE, Beatriz & PETREL (A) & 1595 & - \\
\hline NAVARRO, Bartolomé & ELCHE (A) & 1595 & 6 meses de destierro \\
\hline CAYNOT, Luis & MONFORTE (A) & 1595 & Suspendida \\
\hline Ángela & CREVILLENTE (A) & 1596 & - \\
\hline ALICO, Sebastián & ELDA (A) & 1596 & - \\
\hline JIMÉNEZ, Martín & ELDA (A) & 1596 & - \\
\hline MOSCAPAZ, Ginés & ELDA (A) & 1596 & - \\
\hline QUILEZ, Juan & MONÓVAR (A) & 1596 & - \\
\hline BOCACHO, Francisco & ALICANTE & 1596 & 4 años de destierro \\
\hline CACHAJO, Juan & CREVILLENTE (A) & 1596 & Absuelto \\
\hline ALBADY, Martín & CREVILLENTE (A) & 1597 & - \\
\hline
\end{tabular}


Ramón Doménech Villa. Juicios y sentencias del Tribunal de la Santa Inquisición de Murcia contra ciudadanos residentes en la Corona de Aragón, desde el siglo XV al XIX

\begin{tabular}{|c|c|c|c|}
\hline CANTONA, Esperanza & $\operatorname{COX}(\mathrm{A})$ & 1597 & Suspendida \\
\hline María de Gracia & COX (A) & 1597 & Suspendida \\
\hline YXQUIX, Ángela & CREVILLENTE (A) & 1597 & Suspendida \\
\hline TORRES, Alfonso & ELDA (A) & 1597 & Suspendida \\
\hline BARGUES, Juan & ORIHUELA (A) & 1597 & Suspendida \\
\hline RUIZ, Aldonza & MONÓVAR (A) & S. XVI? & Relajada \\
\hline RUIZ, Blanca & MONÓVAR (A) & S. XVI? & Relajada \\
\hline RUIZ, Pedro & MONÓVAR (A) & S. XVI? & Relajado \\
\hline Farach & ELDA (A) & 1603 & - \\
\hline CIDBÓN, Pedro & MONÓVAR (A) & 1603 & 3 años en galeras \\
\hline VUXARQUI, Martín & MONÓVAR (A) & 1603 & 3 años en galeras \\
\hline AZCARMELIA, Martín & MONÓVAR (A) & 1603 & 4 años en galeras \\
\hline ZUNCAR, Juan & MONÓVAR (A) & 1603 & 4 años en galeras \\
\hline ZEITI, Bernardo? & CREVILLENTE (A) & 1603 & 5 años en galeras \\
\hline ALBACHAR, Francés & MONÓVAR (A) & 1603 & 6 años en galeras \\
\hline CORROI, Juan & MONÓVAR (A) & 1603 & 6 años en galeras \\
\hline MILÁN, Pedro & MONÓVAR (A) & 1603 & 6 años en galeras \\
\hline PUCIZA, Pedro & MONÓVAR (A) & 1603 & 6 años en galeras \\
\hline VIARI, Francés & MONÓVAR (A) & 1603 & 6 años en galeras \\
\hline PAYÁN, Alonso & MONÓVAR (A) & 1603 & 8 años en galeras \\
\hline GARCÍA, Agustina & ORIHUELA (A) & 1611 & Absuelta \\
\hline PÉREZ, Miguel & BUSOT (A) & 1612 & Absuelto \\
\hline REAL, José & VALENCIA & 1612 & Absuelto \\
\hline María & VILLENA (A) & 1612 & Reconciliada \\
\hline SOLAC, María & VILLENA (A) & 1612 & Reconciliada \\
\hline RUIZ, Úrsula & TERESA (CS) & 1615 & Absuelta \\
\hline ZÁRATE, Juan & TERESA (CS) & 1615 & Absuelto \\
\hline BURGOS, Ginés de & ORIHUELA (A) & 1616 & Absuelto \\
\hline GASPAR Pascual & $\begin{array}{l}\text { ROLLEO? } \\
\text { (RELLEU?) }\end{array}$ & 1620 & $\begin{array}{l}200 \text { azotes y } 4 \text { años } \\
\text { en galeras }\end{array}$ \\
\hline MACIA, Pedro (f) & ALICANTE & 1628 & Reclusión \\
\hline MARTÍNEZ, Pablo, esclavo & ORIHUELA (A) & 1631 & Un año de cárcel \\
\hline BESERGA, Juan de (f) & ALICANTE & 1634 & - \\
\hline Antón Jorge (p) & ALICANTE & 1639 & Absuelto \\
\hline ROLAR, Pedro de & ALICANTE & 1643 & Suspendida \\
\hline $\begin{array}{c}\text { Gabriel de Santa María, } \\
\text { esclavo }\end{array}$ & ORIHUELA (A) & 1647 & Absuelto \\
\hline María, esclava & ALICANTE & 1654 & Absuelta \\
\hline ARAL, Pablo & TARRAGONA (T) & 1656 & Absuelto \\
\hline ESTRELLERO, Pedro & ASPE (A) & 1662 & Absuelto \\
\hline Mustafá, esclavo & ORIHUELA (A) & 1663 & Suspendida \\
\hline SEGUÍ, Nicolás & MENORCA (IB) & 1664 & - \\
\hline MUSTAFA, Yusuf & MENORCA (IB) & 1664 & Reconciliado \\
\hline BASTART, Jaime & ALICANTE & 1667 & - \\
\hline Hacen, esclavo & ALICANTE & 1678 & \\
\hline CONCHILLOS, Juan & ALICANTE & 1680 & - \\
\hline CORVINES, Pedro José & ALICANTE & 1680 & - \\
\hline GÓMEZ DE AYALA, María & ALICANTE & 1680 & - \\
\hline $\begin{array}{l}\text { MARTÍNEZ SILVESTRE, } \\
\text { Dorotea }\end{array}$ & ALICANTE & 1680 & - \\
\hline Cristóbal Marco & BIAR (A) & 1680 & - \\
\hline ALBERT, Damián (s) & NOVELDA (A) & 1680 & - \\
\hline AYALA, Pedro Juan de & NOVELDA (A) & 1680 & - \\
\hline
\end{tabular}


Ramón Doménech Villa. Juicios y sentencias del Tribunal de la Santa Inquisición de Murcia contra ciudadanos residentes en la Corona de Aragón, desde el siglo XV al XIX

\begin{tabular}{|c|c|c|c|}
\hline BELENGUER, Luis & NOVELDA (A) & 1680 & - \\
\hline BIENDICHO, Pedro & NOVELDA (A) & 1680 & - \\
\hline Francisco & NOVELDA (A) & 1680 & - \\
\hline GALIANO, Tomás & NOVELDA (A) & 1680 & - \\
\hline PARRA, Antonia & NOVELDA (A) & 1680 & - \\
\hline PARRA, María & NOVELDA (A) & 1680 & - \\
\hline PÉREZ, José & NOVELDA (A) & 1680 & - \\
\hline PÉREZ, Macián & NOVELDA (A) & 1680 & - \\
\hline RUIZ DE VILLENA, Juan & MONÓVAR (A) & 1683 & Relajado (antes de 1683) \\
\hline ELDER, Alejandro & ALICANTE & 1685 & Absuelto? \\
\hline SOLER, José, esclavo & ELCHE (A) & 1687 & 200 azotes y destierro \\
\hline MONTERO, Manuel (p) & ALICANTE & 1702 & Absuelto \\
\hline CERDAN, Joaquín & OLLERÍA (V) & 1754 & - \\
\hline PITARQUE, Pascual & ORIHUELA (A) & 1762 & - \\
\hline PÉREZ, Ginés & ORIHUELA (A) & $15 ? 8$ & Absuelto \\
\hline PAYOL, Juan & ASPE (A) & $1566-67$ & $\begin{array}{l}2 \text { meses de cárcel y multa de } \\
30 \text { ducados }\end{array}$ \\
\hline AMAR, Gaspar & ASPE (A) & $1566-67$ & $\begin{array}{l}6 \text { meses de cárcel Y } \\
\text { multa de } 6000 \mathrm{mrs} \text {. }\end{array}$ \\
\hline ALICANTI GARLES, Juan & NOVELDA (A) & $1566-67$ & Reclusión \\
\hline Leonor & ASPE (A) & $1571-80$ & - \\
\hline BERNIZO, Leonor & $\operatorname{ELDA}(\mathrm{A})$ & $1584-86$ & Cárcel perpetua \\
\hline DACA, Juan & MONFORTE (A) & $1593-94$ & Relajado \\
\hline MAYAYO, María & ASPE (A) & $1594-1603$ & Cárcel perpetua \\
\hline MICHIL (o MILICH), Baltasar & PETREL (A) & $1594-95$ & Suspendida \\
\hline TETE, Ginés & ASPE (A) & $1594-97$ & Azotes y 5 años en galeras \\
\hline FARACH, Juan & CREVILLENTE (A) & $1595-97$ & Suspendida \\
\hline MORALES, Gaspar de & ORIHUELA (A) & $1631-33$ & Suspendida \\
\hline TORRE, León de la & ALICANTE & $1680-83$ & Falleció \\
\hline ARBICO, Felipe Luis (it) & ALICANTE & $1750 ?$ & - \\
\hline
\end{tabular}


Ramón Doménech Villa. Juicios y sentencias del Tribunal de la Santa Inquisición de Murcia contra ciudadanos residentes en la Corona de Aragón, desde el siglo XV al XIX

\section{JUDAIZANTES}

\begin{tabular}{|c|c|c|c|}
\hline APELLIDO Y NOMBRE & $L O C A L I D A D$ & $A \tilde{\mathrm{N}} O$ & $S E N T E N C I A$ \\
\hline MINEZ, Juan & VILLENA (A) & 1476 & Reconciliado \\
\hline CASTILlO, Pedro del & VILLENA (A) & 1496 & Relajado \\
\hline FERNANDEZ, Leonor (p) & VILLENA (A) & 1498 & Relajada en estatua \\
\hline DÍAZ, María & VILLENA (A) & 1502 & Relajada en estatua \\
\hline HERNÁNDEZ, Elvira & VILLENA (A) & 1502 & Relajada en estatua \\
\hline $\begin{array}{c}\text { SÁNCHEZ DE ARBOLEDA, } \\
\text { Diego }\end{array}$ & VILLENA (A) & 1502 & Relajado en estatua \\
\hline $\begin{array}{l}\text { SÁNCHEZ DE ARBOLEDA, } \\
\text { Gonzalo }\end{array}$ & VILLENA (A) & 1502 & Relajado en estatua \\
\hline $\begin{array}{l}\text { SÁNCHEZ DE ARBOLEDA, } \\
\text { Luis }\end{array}$ & VILLENA (A) & 1502 & Relajado en estatua \\
\hline $\begin{array}{c}\text { GONZÁLEZ DE TOLEDO, } \\
\text { Martín }\end{array}$ & VILLENA (A) & 1503 & Relajado en estatua \\
\hline Leonor & VILLENA (A) & 1503 & Relajada en estatua \\
\hline TRISTÁN, Bernal & VILLENA (A) & 1503 & Relajado en estatua \\
\hline TRISTÁN, Manuel & VILLENA (A) & 1503 & Relajado en estatua \\
\hline MARTÍNEZ, Juan & VILLENA (A) & 1565 & Un año de cárcel \\
\hline ALEGRÍA, Juan de & AYORA (V) & 1580 & - \\
\hline RUIZ, Leonor & ALICANTE & 1581 & Reconciliada \\
\hline BUENDÍA, Constanza de & VILLENA (A) & 1581 & Relajada en estatua \\
\hline RODRÍGUEZ, María & ALICANTE & 1611 & - \\
\hline FERNANDEZ, Leonor (p) & $\operatorname{SAX}(\mathrm{A})$ & 1611 & Suspendida \\
\hline MÉNDEZ, Ana (p) & JÁTIVA (V) & 1620 & Un año de cárcel \\
\hline RODRÍGUEZ, Constanza (P) & VILLENA (A) & 1620 & 100 azotes y cárcel perpetua \\
\hline FERNÁNDEZ, Leonor (p) & ALICANTE & 1625 & Suspendida \\
\hline NIETO, Diego $(\mathrm{p})$ & ALICANTE & 1625 & Suspendida \\
\hline BÁEZ, Catalina (p) & ORIHUELA (A) & 1625 & Suspendida \\
\hline LÓPEZ, Hernando (p) & ORIHUELA (A) & 1625 & Suspendida \\
\hline RODRÍGUEZ, Antón & ORIHUELA (A) & 1625 & Suspendida \\
\hline LÓPEZ, Ana (p) & ALICANTE & 1654 & 4 años de destierro \\
\hline RODRÍGUEZ, Cosme (p) & ALICANTE & 1656 & - \\
\hline MÉNDEZ DE OCAÑA, Alvaro & ALICANTE & 1664 & Suspendida \\
\hline HERNÁNDEZ, Gaspar & ELCHE (A) & 1664 & - \\
\hline DUARTE, Beatriz (p) & VALENCIA & 1667 & - \\
\hline DUARTE, Catalina (p) & VALENCIA & 1667 & - \\
\hline MONTOYA, Pedro de (p) & VALENCIA & 1667 & - \\
\hline ÁlVAREZ, Francisco & ORIHUELA (A) & 1680 & Falleció \\
\hline ÁLVAREZ, Rafael (p) & ORIHUELA (A) & 1680 & - \\
\hline ÁLVAREZ FRANCO, Francisco & ELDA (A) & 1682 & Falleció \\
\hline CÓRDOBA, Manuel & ALICANTE & 1689 & - \\
\hline PAZ, Beatriz de la & ALICANTE & 1689 & - \\
\hline VELASCO, Dionisio & ALICANTE & 1692 & - \\
\hline BURGOS, José de & ALICANTE & 1702 & - \\
\hline BURGOS, Juan de & ALICANTE & 1702 & - \\
\hline FIGUEROA, Margarita de (P) & ORIHUELA (A) & 1720 & - \\
\hline GARCÍA, Clara & ORIHUELA (A) & 1720 & - \\
\hline MELO, Francisca & ORIHUELA (A) & 1720 & - \\
\hline MELO, Francisco & ORIHUELA (A) & 1720 & 300 azotes y cárcel perpetua \\
\hline MELO, Mencía & ORIHUELA (A) & 1720 & - \\
\hline RUIZ DE MENDOZA, Antón & ORIHUELA (A) & 1720 & - \\
\hline ANDRADE, Guiomar de (P) & ALICANTE & 1721 & 200 azotes y cárcel perpetua \\
\hline VÁZQUEZ LÓPEZ, Rafael & ELCHE (A) & 1721 & - \\
\hline FIGUEROA, Isabel (p) & ORIHUELA (A) & 1721 & Cárcel perpetua \\
\hline LÓPEZ VÁZQUEZ, María & ORIHUELA (A) & 1722 & Cárcel perpetua \\
\hline MÉNDEZ, Mencía (p) & ORIHUELA (A) & 1723 & 200 azotes y cárcel perpetua \\
\hline LÓPEZ, Manuel (p) & JÁTIVA (V) & $1621-22$ & Suspendida \\
\hline ALVAREZ, Juan Diego (p) & ORIHUELA (A) & $1678-80$ & - \\
\hline FRANCO, Francisco & ORIHUELA (A) & $1678-80$ & Falleció \\
\hline MELO, Fernando & ORIHUELA (A) & $1692-721$ & - \\
\hline PAZ, Francisco Alfonso de & ALICANTE & $1720-22$ & 200 azotes y cárcel perpetua \\
\hline GARCÍA, Manuel & ORIHUELA (A) & $1721-24$ & - \\
\hline GARCÍA ARCHENT, Juan & ALICANTE & $1722-23$ & - \\
\hline LÓPEZ VÁZQUEZ, Rodrigo & ELCHE (A) & $1724-25$ & - \\
\hline
\end{tabular}

SCRIPTA, Revista internacional de literatura i cultura medieval i moderna, núm. 15 / juny 2020 / pp. 175-214 
Ramón Doménech Villa. Juicios y sentencias del Tribunal de la Santa Inquisición de Murcia contra ciudadanos residentes en la Corona de Aragón, desde el siglo XV al XIX

III SOLICITANTES

\begin{tabular}{|c|c|c|c|}
\hline APELLIDO Y NOMBRE & LOCALIDAD & $A \tilde{N} O$ & SENTENCIA \\
\hline PASTOR, Gaspar (OFM) & ALICANTE & 1567 & 6 meses de reclusión \\
\hline JIMENO (S) & VILLENA (A) & 1574 & \\
\hline GARCÍA, Francisco (OP) & AYORA (V) & 1580 & - \\
\hline GARCÍA, Pedro (S) & AYORA (V) & 1580 & - \\
\hline Maras (OFM) & AYORA (V) & 1580 & - \\
\hline MASQUESA, Enrique (OP) & AYORA (V) & 1580 & - \\
\hline AGUILAR, Marcos de (OFM) & AYORA (V) & 1584 & Reprendido \\
\hline BARULLES, Pedro (OC) & ORIHUELA (A) & 1596 & - \\
\hline GARCÍA, Jerónimo (OP) & AYORA (V) & 1597 & - \\
\hline CASTILLO, Juan del (S) & NOVELDA (A) & 1597 & - \\
\hline BERRUELOS, Gaspar (OP) & AYORA (V) & $1597-98$ & - \\
\hline ALCAYNA, Vicente (OP) & AYORA (V) & 1599 & - \\
\hline BLANES, Pedro (OFM) & ELCHE (A) & 1611 & Suspendida \\
\hline OREL (OM) & ELCHE (A) & 1611 & Suspendida \\
\hline ORTIZ, Francisco (OFM) & ELCHE (A) & 1611 & Suspendida \\
\hline MARTÍNEZ (S) & GUARDARMAR (A) & 1611 & - \\
\hline MÁRQUEZ, Martín (OM) & ELCHE (A) & $1611-12$ & 5 años de destierro \\
\hline DÍAZ NAVARRO, Damián (OFM) & ALICANTE & $1613-15$ & 4 años de destierro \\
\hline PERTEGÁS (OFM) & MUCHAMIEL (A) & 1618 & - \\
\hline MIRALLES, Miguel (S) & ELCHE (A) & 1635 & Suspendida \\
\hline TIBI, Juan (OFM Cap) & ORIHUELA (A) & 1661 & - \\
\hline Faustino de Benavente (OV) & MUCHAMIEL (A) & 1664 & Un año de reclusión \\
\hline PAZ, Alberto de la (OP) & AYORA (V) & 1669 & - \\
\hline RAMIA, Diego de (OP) & AYORA (V) & 1669 & - \\
\hline MARTÍNEZ, Juan (OFM) & ELCHE (A) & 1669 & - \\
\hline NAVARRO, Tomás (OP) & LUCHENTE (V) & 1669 & - \\
\hline Bartolomé de Cartagena (OM) & ORIHUELA (A) & 1669 & - \\
\hline MOSCARDÓ, Francisco (OP) & ALICANTE & 1672 & Un año de reclusión \\
\hline PÉREZ, Antón (OFM) & VILLENA (A) & 1676 & - \\
\hline MARCO, Cristóbal (S) & $\operatorname{BIAR}(\mathrm{A})$ & 1679 & - \\
\hline RODRÍGUEZ, José (OSST) & $\operatorname{ASPE}(\mathrm{A})$ & $1687-88$ & - \\
\hline AGULLÓ, José (OFM) & ORIHUELA (A) & $1690-704$ & - \\
\hline GUILLÉN, José (OFM) & ORITO & 1699 & - \\
\hline ALENDA, Leandro (OFM) & ORIHUELA (A) & 1701 & - \\
\hline OROZCO, Juan (OFM) & GALLINERA (A) & 1709 & _- \\
\hline GARCÍA, Luis (OFM) & ORIHUELA (A) & $1707-9$ & - \\
\hline GRANEL, Crisóstomo (OP) & ALICANTE & 1709 & - \\
\hline GAIBIEL, José (OFM) & MONÓVAR (A) & 1713 & - \\
\hline CONTRERAS, Diego (S) & PATERNA (V) & 1715 & - \\
\hline $\begin{array}{l}\text { NAVARRO Y PACHECO, José } \\
\text { (OFM) }\end{array}$ & ELCHE (A) & 1729 & _- \\
\hline RAMÓN, Jaime (S) & VILLENA (A) & 1730 & - \\
\hline CERDÁ, Pablo (S) & ORIHUELA (A) & 1734 & - \\
\hline ORTUÑO, Jerónimo (OC) & ORIHUELA (A) & 1741 & - \\
\hline PERPIÑÁN, Manuel (OM) & ELCHE (A) & $1737-44$ & - \\
\hline ARTIGUES, Cristóbal (OFM) & AYORA (V) & $1750-1777$ & - \\
\hline PUJALT Y DOLZ, Agustín (S) & ALICANTE & 1766 & -_ \\
\hline PAYÁ, Miguel (OP) & ELCHE (A) & 1767 & - \\
\hline VICENT, Juan (S) & ORIHUELA (A) & $1768-74$ & - \\
\hline GONZÁLVEZ, Gervasio (OC) & ORIHUELA (A) & 1769 & - \\
\hline AGULLÓ, José (OFM) & ORIHUELA (A) & 1779 & - \\
\hline NAVARRO, José (OSST) & ORIHUELA (A) & 1781 & - \\
\hline SEMPERE, Juan (S) & NOVELDA (A) & 1783 & - \\
\hline MIRÓ, Blas (OC) & ORIHUELA (A) & 1783 & - \\
\hline PÉREZ, Pedro Pascual (S) & EL GRAO (V) & 1785 & -- \\
\hline MARTÍNEZ, José (OFM) & ELCHE (A) & $1786-87$ & - \\
\hline PUSOL, Francisco (OFM) & ALICANTE & 1788 & - \\
\hline ALBERTOS, Francisco (S) & ELCHE (A) & 1794 & - \\
\hline FERRER, Francisco Antonio (S) & ELCHE (A) & 1806 & - \\
\hline PONT, Francisco (OSA) & ALICANTE & SIGLO XVIII & - \\
\hline PUCHE, Salvador (S) & ORIHUELA (A) & SIGLO XVIII & - \\
\hline MAS, José (S) & ORIHUELA (A) & 1807 & - \\
\hline RIPOLL, José (S) & ORIHUELA (A) & 1807 & - \\
\hline GIRONÉS, Pedro (OFM) & ALICANTE & 1816 & - \\
\hline ESCRIBÁ, Domingo (OP) & ALICANTE & 1819 & - \\
\hline GALVIS, Juan (S) & ELCHE (A) & 1819 & - \\
\hline GÓMEZ, Esteban (OSST) & ORIHUELA (A) & 1819 & - \\
\hline $\begin{array}{l}\text { ONTENIENTE, Mariano (OFM } \\
\text { CAP) }\end{array}$ & ORIHUELA (A) & 1819 & _- \\
\hline ZERDÁ, Francisco (S) & VILLENA (A) & 1819 & - \\
\hline
\end{tabular}

SCRIPTA, Revista internacional de literatura i cultura medieval i moderna, núm. 15 / juny 2020 / pp. 175-214 ISSN: 2340-4841 · doi:/ SCRIPTA.16.19250 
Ramón Doménech Villa. Juicios y sentencias del Tribunal de la Santa Inquisición de Murcia contra ciudadanos residentes en la Corona de Aragón, desde el siglo XV al XIX

\section{RELIGIOSOS CASADOS}

\begin{tabular}{|c|c|c|c|}
\hline APELLIDO Y NOMBRE & LOCALIDAD & AÑO & SENTENCIA \\
\hline BOTELLA, Gaspar (JER) & ELCHE (A) & 1565 & Reclusión \\
\hline APARICIO, Sebastián (OSA) & ELCHE (A) & 1642 & 4 años en galeras \\
\hline CALATAYUD, Manuel (OFM Cap) & ALICANTE & 1725 & - \\
\hline
\end{tabular}

SCRIPTA, Revista internacional de literatura i cultura medieval i moderna, núm. 15 / juny 2020 / pp. $175-214$ ISSN: 2340-4841 · doi:/ SCRIPTA.16.19250 
Ramón Doménech Villa. Juicios y sentencias del Tribunal de la Santa Inquisición de Murcia contra ciudadanos residentes en la Corona de Aragón, desde el siglo XV al XIX

\section{BÍGAMOS}

\begin{tabular}{|c|c|c|c|}
\hline APELLIDO Y NOMBRE & LOCALIDAD & $A \tilde{N} O$ & SENTENCIA \\
\hline MARTÍNEZ, Juan & ALBATERA (A) & 1562 & 200 azotes \\
\hline RAVADÁN, Sebastián & ORIHUELA (A) & 1562 & 200 azotes y 2 años en galeras \\
\hline IRLE, Pedro de & ALICANTE & 1563 & Azotes \\
\hline RÍOS, Gaspar de los & COCENTAINA (A) & 1563 & 100 azotes y 2 años en galeras \\
\hline CELDRAN, Luis & ORIHUELA (A) & 1563 & 200 azotes y 2 años de destierro \\
\hline VICENTE, Úrsula & ORIHUELA (A) & 1563 & 300 Azotes \\
\hline FUENTE, Diego de la & ORIHUELA (A) & 1564 & Sacado a la vergüenza \\
\hline LÓPEZ, Miguel & ORIHUELA (A) & 1565 & Absuelto \\
\hline PÉREZ, Isabel & ORIHUELA (A) & 1567 & Abjura de levi \\
\hline JUAN ALONSO & MONÓVAR (A) & 1572 & 4 años en galeras \\
\hline TARI, Jaime & ELCHE (A) & 1633 & Suspendida \\
\hline MARTÍNEZ DE AMEZQUITA, Tomás & ORIHUELA (A) & $1652-54$ & 200 azotes y 5 años en galeras \\
\hline OLAZABAL, Miguel de & ALICANTE & 1667 & - \\
\hline TONDOS, Cristóbal de & $\operatorname{ELDA}(\mathrm{A})$ & $1673-74$ & 200 azotes y 5 años en galeras \\
\hline REQUENA, Josefa & ALICANTE & 1678 & - \\
\hline VERGARA, Pedro Antonio de & ALICANTE & 1680 & - \\
\hline LÓPEZ, Esperanza & ORIHUELA (A) & $1680-82$ & 100 azotes y 4 años de destierro \\
\hline FERNANDEZ, Tomás & ALICANTE & 1683 & - \\
\hline FERRIS, Francisco & ALICANTE & 1695 & 100 azotes y 3 años en galeras \\
\hline VARGAS, Diego Francisco & ALICANTE & 1702 & Destierro perpetuo \\
\hline VERDI, José & ELCHE (A) & 1751 & - \\
\hline ESCRIBANO, José & MONFORTE $(\mathrm{A})$ & 1754 & - \\
\hline MASQUETA, Ana María & ELCHE (A) & $1762-72$ & - \\
\hline BRIONES, Josefa & ALICANTE & 1768 & - \\
\hline CABRERA, Manuela & ALICANTE & 1770 & - \\
\hline MARTÍNEZ, José & ALICANTE & 1770 & - \\
\hline SIRVENT, Francisco Javier & MONFORTE (A) & $1772-76$ & - \\
\hline BRICEÑO, Juan José & ALICANTE & 1804 & - \\
\hline
\end{tabular}


Ramón Doménech Villa. Juicios y sentencias del Tribunal de la Santa Inquisición de Murcia contra ciudadanos residentes en la Corona de Aragón, desde el siglo XV al XIX

VI FORNICARIOS

\begin{tabular}{|c|c|c|c|}
\hline APELLIDO Y NOMBRE & LOCALIDAD & $A \tilde{N} O$ & SENTENCIA \\
\hline ARAGÓN, Domingo de & ORIHUELA (A) & 1565 & 2 años de destierro \\
\hline LÓPEZ, Pedro & VALENCIA & 1573 & Suspendida \\
\hline María de la Trinidad & ALICANTE & 1579 & 100 azotes \\
\hline PARRAS, Miguel & CALLOSA (A) & 1580 & Reprendido \\
\hline GONZÁLEZ, Gaspar & ELCHE (A) & 1580 & - \\
\hline RUIZ, Jaime & LA GRANJA DE ROCAMORA (A) & 1588 & 200 azotes \\
\hline HIDALGO, Domingo & VALENCIA & 1588 & 2 años de destierro \\
\hline CHINCHILLA, Pedro & $\operatorname{ELCHE}(\mathrm{A})$ & 1594 & 100 azotes y 2 años de destierro \\
\hline RIPOLL, Jaime & ELCHE (A) & 1594 & 2 años de destierro \\
\hline ROBLES, Alonso de & ELCHE (A) & 1594 & 100 azotes y 2 años de destierro \\
\hline BERENGUELA, Luisa & ORIHUELA (A) & 1594 & Abjura de levi \\
\hline OLIVARES, Bartolomé & ALICANTE & $1595-96$ & Un año de destierro \\
\hline ROBLES, Juan & ORIHUELA (A) & 1610 & Suspendida \\
\hline LÓPEZ, Diego & ELCHE (A) & 1611 & Suspendida \\
\hline SÁNCHEZ, Ginés & ORIHUELA (A) & 1611 & Reprendido \\
\hline ROCAMORA, Francisco & ORIHUELA (A) & 1734 & Remitida a Valencia \\
\hline LÓPEZ BUENO, Francisco Javier (S) & ORIHUELA (A) & 1777 & Se remitió a Valencia \\
\hline LAMAITRE, Martín (f) & ALICANTE & 1779 & Se remitió a Valencia \\
\hline
\end{tabular}


Ramón Doménech Villa. Juicios y sentencias del Tribunal de la Santa Inquisición de Murcia contra ciudadanos residentes en la Corona de Aragón, desde el siglo XV al XIX

\section{SUPERSTICIOSOS}

\begin{tabular}{|c|c|c|c|}
\hline APELLIDO Y NOMBRE & LOCALIDAD & $A \tilde{N} O$ & SENTENCIA \\
\hline ARAGÓN, Felipe de & ELCHE (A) & 1563 & - \\
\hline BERBERUZ, Juan & ELDA (A) & 1565 & $\begin{array}{l}400 \text { azotes, cárcel perpetua y multa de } \\
50 \text { ducados }\end{array}$ \\
\hline Adoni & AYORA (V) & 1580 & Penitenciado \\
\hline OLIVERA & VILLENA (A) & 1580 & - \\
\hline PRADOS, Mariana & ALICANTE & 1611 & Suspendida \\
\hline Antona & CALLOSA (A) & 1611 & Suspendida \\
\hline JÁTIVA, Martín & CALLOSA (A) & 1611 & Suspendida \\
\hline MANRESA, Catalina & CALLOSA (A) & 1611 & Suspendida \\
\hline POMARES, Viuda de & ELCHE (A) & 1611 & - \\
\hline IBÁÑEZ, Jaime & ORIHUELA (A) & 1611 & Suspendida \\
\hline PASTORA, Isabel & ORIHUELA (A) & 1611 & Suspendida \\
\hline RUGUERA, Leonor & ORIHUELA (A) & 1611 & - \\
\hline LÓPEZ, Cecilia & ALICANTE & 1613 & 100 azotes y 3 años de destierro \\
\hline ESTEBAN, Florinda & ORIHUELA (A) & 1613 & 3 años de destierro \\
\hline FLORES, Bárbara & ORIHUELA (A) & 1613 & 100 azotes y 3 años de destierro \\
\hline PERALTA, Fernando & ALICANTE & 1614 & 100 azotes y 10 años de destierro \\
\hline AGRAMONTE, Vicente & GANDÍA (V) & 1615 & Reprendido \\
\hline SÁNCHEZ, Juana & ORIHUELA (A) & 1620 & 8 años de destierro \\
\hline AGUILERA, Diego de & ALICANTE & 1624 & Suspendida \\
\hline ÁlVAREZ, Francisco & ALICANTE & 1634 & Reprendido \\
\hline CORDERO, Josefa & ALICANTE & $1626-43$ & - \\
\hline GONZÁLEZ, Jaime & ALICANTE & 1634 & Reprendido \\
\hline GUILLÉN, Angela & ALICANTE & 1634 & Reprendida \\
\hline JUAN CARPENA, Isabel & ALICANTE & 1634 & Reprendida \\
\hline JUAN, Felipe & ALICANTE & 1634 & Reprendida \\
\hline MARCO, Francisco Juan & ALICANTE & 1634 & Reprendida \\
\hline NAVARRO, Elvira & ALICANTE & 1634 & Reprendida \\
\hline NAVARRO, Eugenio & ALICANTE & 1634 & Reprendido \\
\hline SERRANO, Francisco & ALICANTE & 1634 & Reprendido \\
\hline HERRERA, Ginesa & ORIHUELA (A) & 1637 & Reprendida \\
\hline SÁNCHEZ, Alonso & TABARCA (A) & 1640 & - \\
\hline BARCELONA, Ana & ALICANTE & 1643 & 6 años de destierro \\
\hline GÓMEZ, María & ORIHUELA (A) & 1643 & Reprendida \\
\hline FERNÁNDEZ, José & ALICANTE & 1654 & Reprendido \\
\hline JUAN, María Josefa & ALICANTE & 1654 & - \\
\hline OLMO, María del & ALICANTE & 1654 & Reprendida \\
\hline MATA, Catalina & ORIHUELA (A) & 1654 & Suspendida \\
\hline HERNÁNDEZ, Beatriz & ORIHUELA (A) & 1654 & Suspendida \\
\hline ROMERO, Ana & ORIHUELA (A) & 1654 & 4 años de destierro \\
\hline TOMÁs, Josefa & VILLENA (A) & 1656 & Advertida \\
\hline ESCAMILLA, Angela & ELCHE (A) & 1657 & 2 años de destierro \\
\hline GARCÍA, Ana & ELCHE (A) & 1657 & 4 años de destierro \\
\hline MACABEL, María & ELCHE (A) & 1657 & Suspendida \\
\hline MIRALLES, Florentina & ELCHE (A) & 1657 & 3 años de destierro \\
\hline PÉREZ, Clara & ORIHUELA (A) & 1657 & Reprendida \\
\hline PÉREZ, Guiomar & ORIHUELA (A) & 1657 & Reprendida \\
\hline FERNÁNDEZ, Josefa & ALICANTE & 1658 & Suspendida \\
\hline LÓPEZ, Pascuala & ALICANTE & 1658 & Suspendida \\
\hline CATALÁN, Martín & AYORA (V) & 1658 & Reprendido \\
\hline MEDINA, Francisco (OFM) & AYORA (V) & 1658 & Reprendido \\
\hline RUBIO, Lucas & AYORA (V) & 1658 & Reprendido \\
\hline FRANCISCA & ALICANTE & 1679 & - \\
\hline MARÍA & ALICANTE & 1679 & - \\
\hline MARÍA BENEDICTO & ALICANTE & 1680 & - \\
\hline PASTOR, Francisca & ALICANTE & 1680 & - \\
\hline LÓPEZ, José & ORIHUELA (A) & 1681 & Suspendida \\
\hline $\begin{array}{c}\text { HERNÁNDEZ, Rosa } \\
\text { Bonifacia }\end{array}$ & ORIHUELA (A) & 1700 & 200 azotes y 4 años de destierro \\
\hline SANZ, Francisca & ORIHUELA (A) & 1706 & Reclusión \\
\hline GALAN, Silvestre & TORREVIEJA (A) & 1711 & Desterrado \\
\hline ARNAU, Juana & VILLENA (A) & 1732 & - \\
\hline SALA, Juan & NOVELDA & 1733 & - \\
\hline MARCO, José & ORIHUELA & $1735 / 39$ & - \\
\hline MARTÍNEZ, Diego & ALICANTE & $1735 / 42$ & - \\
\hline NAVARRO, Miguel & ORIHUELA (A) & 1737 & - \\
\hline MOYA, Joaquina & VILLENA (A) & 1738 & - \\
\hline MON, Luis de (f) & ALICANTE & 1740 ? & - \\
\hline GARBO, María & ORIHUELA (A) & 1742 & Suspendida \\
\hline HERVÁS, Manuel & ORIHUELA (A) & 1742 & - \\
\hline DASI, Vicenta & ORIHUELA (A)? & 1742 & - \\
\hline DABO, Antonia & CALLOSA (A) & 1753 & - \\
\hline FOLLENA, Josefa & ORIHUELA (A) & 1754 & 200 azotes y 3 años de destierro \\
\hline EMBID, Diego & ELCHE (A) & 1759 & - \\
\hline FARY, Josefa María Rita & ELCHE (A) & 1761 & - \\
\hline María de la Rosa & ORIHUELA (A) & 1764 & - \\
\hline $\begin{array}{l}\text { GRACE, María de los } \\
\text { Angeles }\end{array}$ & ORIHUELA (A) & 1766 & - \\
\hline TROLL, Ana María & ORIHUELA (A) & 1769 & - \\
\hline FRANCO, Mosa & ORIHUELA (A) & 1805 & - \\
\hline CASTEL, María Antonia & ELCHE (A) & 1819 & - \\
\hline FLORENTÍN, Josefa & ALICANTE & & 5 años de destierro \\
\hline
\end{tabular}

SCRIPTA, Revista internacional de literatura i cultura medieval i moderna, núm. 15 / juny 2020 / pp. 175-214 ISSN: 2340-4841 · doi:/ SCRIPTA.16.19250 
Ramón Doménech Villa. Juicios y sentencias del Tribunal de la Santa Inquisición de Murcia contra ciudadanos residentes en la Corona de Aragón, desde el siglo XV al XIX

VIII BLASFEMOS

\begin{tabular}{|c|c|c|c|}
\hline APELLIDO Y NOMBRE & LOCALIDAD & $A \tilde{N} O$ & SENTENCIA \\
\hline PERPIÑÁN, Francisco de & ELCHE (A) & 1565 & 100 Azotes y 5 años de destierro \\
\hline VAYABÁN, Gaspar & $\operatorname{ELCHE}(\mathrm{A})$ & 1567 & 200 azotes \\
\hline GENTILES, Penigasque (f) & $\operatorname{COX}(\mathrm{A})$ & 1568 & 100 azotes \\
\hline Miguel Ángel & VALENCIA & 1571 & 2 años de destierro \\
\hline SEBA, Gregorio & MUCHAMIEL (A) & 1573 & Reprendido \\
\hline BLASCO, Bartolomé & VALENCIA & 1573 & Reprendido \\
\hline CÁMARA, Pedro de la & AYORA (V) & 1580 & - \\
\hline JUAN, Isabel & ORIHUELA (A) & 1592 & Abjura de levi \\
\hline BORXAT, Leonardo & ALICANTE & 1594 & Reprendido \\
\hline ALMANSA, Miguel de & ALICANTE & 1596 & Reprendido \\
\hline SÁNCHEZ, Juan & ASPE (A) & 1610 & Reprendido \\
\hline PASTOR, Tomás & ALICANTE & 1611 & Suspendida \\
\hline ESCÁMEZ, Marco & ALMORADÍ (A) & 1611 & Suspendida \\
\hline MARCO, Antonio & CALLOSA (A) & 1611 & Suspendida \\
\hline GONZÁLVEZ, Gaspar & ELCHE (A) & 1611 & Reprendido \\
\hline Una prostituta & ELCHE (A) & 1611 & - \\
\hline QUIRALTE, Francisco & PATERNA (V) & 1611 & 2 meses de destierro \\
\hline GANGA, Martín & ORIHUELA (A) & 1612 & Reprendido \\
\hline ABÓ, Esteban de & NOVELDA (A) & $1611-13$ & Reprendido \\
\hline FALAGUERES, Antón & ORIHUELA (A) & 1613 & Reprendido \\
\hline HERNÁNDEZ, Diego & VILLENA (A) & 1613 & Reprendido \\
\hline FERNÁNDEZ, Martín & ORIHUELA (A) & 1615 & Absuelto \\
\hline BATLE, Jaime & ORIHUELA (A) & 1616 & Reprendido \\
\hline SIERRA, Domingo de & CASTALLA (A) & 1621 & 200 azotes y 4 años en galeras \\
\hline LÓPEZ, Juan & ALICANTE & 1632 & Reprendido \\
\hline BERENGUER, Jaime & ALICANTE & 1634 & - \\
\hline BERCEBA, Juan (f) & ALICANTE & 1635 & 10 años de destierro \\
\hline PÉREZ, Antón & ORIHUELA (A) & 1644 & Reprendido \\
\hline SOLER, Francisco & ORIHUELA (A) & 1654 & 10 años de destierro \\
\hline CÓRDOBA, Juan de & ORIHUELA (A) & 1655 & Reprendido \\
\hline DOMÉNECH, Antón (S) & VILLENA (A) & 1664 & Suspendida \\
\hline DUQUE, José & ORIHUELA (A) & 1736 & - \\
\hline BORO Y DUQUE, José & ORIHUELA (A) & 1737 & - \\
\hline BOZO Y DUQUE, José & ORIHUELA (A) & 1737 & - \\
\hline NAVARRO, Miguel & ORIHUELA (A) & 1737 & - \\
\hline MARTÍNEZ, Diego & ALICANTE & 1745 & - \\
\hline ESCRIBÁ, Miguel & ORIHUELA (A) & $1738-42$ & - \\
\hline BERENGUER, Luis & ALICANTE & $1757-58$ & - \\
\hline FUENTES, José & ALICANTE & 1762 & - \\
\hline ALIAGA, Antón & ORIHUELA (A) & $1767-69$ & - \\
\hline BARBERÁ, Francisco & $\operatorname{ELDA}(\mathrm{A})$ & $1777-80$ & - \\
\hline GIL, Ramón & ALMORADÍ (A) & 1780 & - \\
\hline
\end{tabular}


Ramón Doménech Villa. Juicios y sentencias del Tribunal de la Santa Inquisición de Murcia contra ciudadanos residentes en la Corona de Aragón, desde el siglo XV al XIX

\section{SACRÍLEGOS}

\begin{tabular}{|c|c|c|c|}
\hline APELLIDO $Y$ NOMBRE & LOCALIDAD & AÑ $\boldsymbol{S}$ & SENTENCIA \\
\hline AJAMORA, esclava & ELCHE (A) & 1625 & 1628 azotes \\
\hline ÁLVAREZ, León & ORIHUELA (A) & 1634 & Un año de destierro y multa de 1000 mrs. \\
\hline GONZÁLEZ, Jaime & ORIHUELA (A) & 1634 & Reprendido \\
\hline JUAN, Felipe & ORIHUELA (A) & 1635 & 4 años de destierro \\
\hline BERENGUER, Jaime & ALICANTE & 1691 & Reprendido \\
\hline MARTÍNEZ, Juan & ALICANTE & $1781-82$ & - \\
\hline JOAQUÍN ANTÓN & ELCHE (A) & Siglo XVIII & - \\
\hline GALIPIENZO, José & CREVILLENTE (A) & - \\
\hline GALLARDO, Francisco & CREVILLENTE (A) & Siglo XVIII & - \\
\hline QUESADA, José & CREVILLENTE (A) & Siglo XVIII & 1819 \\
\hline
\end{tabular}

\section{IRREVERENTES}

\begin{tabular}{|c|c|c|c|}
\hline APELLIDO Y NOMBRE & LOCALIDAD & AÑO & SENTENCIA \\
\hline HACULA, Gracia & NOVELDA (A) & 1568 & 100 azotes \\
\hline HERNÁNDEZ, Diego, esclavo & NOVELDA (A) & 1570 & Sacado a la vergüenza \\
\hline ALONSO, Manuel & ORIHUELA (A) & 1819 & - \\
\hline
\end{tabular}

\section{DELITOS CONTRA EL SANTO OFICIO}

\begin{tabular}{|c|c|c|c|}
\hline APELLIDO $Y$ NOMBRE & LOCALIDAD & AÑ & SENTENCIA \\
\hline ORTÍN, Juan Bautista & AYORA (V) & 1576 & 3 meses de destierro \\
\hline PICARRO, Juan (OFM) & ALICANTE & 1580 & Reprendido \\
\hline MALLA, Pedro (S) & ELCHE (A) & 1580 & Gravemente reprendido \\
\hline INGLÉS, Juan & ORIHUELA (A) & 1581 & 6 ducados de multa \\
\hline SORIA, Francés & ORIHUELA (A) & 1595 & Multa de 4000 mrs. \\
\hline FERRER, Ginés & ORIHUELA (A) & 1616 & 3 años de destierro \\
\hline ESCRIVÁ, Domingo (OP) & ALICANTE & 1631 & Reprendido \\
\hline ESTEBAN, Pedro (S) & VILLENA (A) & $1632-33$ & Reprendido \\
\hline PERPIŃÁN, Claudio & ELCHE (A) & 1703 & - \\
\hline RUIZ, Egidio & ELCHE (A) & 1703 & - \\
\hline FLOIRIA, Manuel (OP) & AYORA (V) & 1779 & - \\
\hline SANTA MARÍA, José & ORIHUELA (A) & 1815 & - \\
\hline
\end{tabular}


Ramón Doménech Villa. Juicios y sentencias del Tribunal de la Santa Inquisición de Murcia contra ciudadanos residentes en la Corona de Aragón, desde el siglo XV al XIX

XII VARIOS

\begin{tabular}{|c|c|c|c|c|}
\hline APELLIDO Y NOMBRE & LOCALIDAD & AÑO & DELITO & SENTENCIA \\
\hline $\begin{array}{c}\text { JUÁREZ DE RIBERA, Pedro } \\
(\mathrm{p})\end{array}$ & ALICANTE & 1631 & Quiso pasar a Francia sin licencia & Absuelto \\
\hline MARTÍNEZ, Tomás & ORIHUELA (A) & 1707 & Escribió un libro & 6 años de destierro \\
\hline MOLTO, Urbano (OFM) & ELDA (A) & 1709 & Exhortaba a la rebelión & - \\
\hline CERDÁ, Tomás & ASPE (A) & 1762 & Hechos heréticos & - \\
\hline Laureano Antón & MUCHAMIEL (A) & 1816 & Desacato a la iglesia & - \\
\hline
\end{tabular}

\section{DELITOS DESCONOCIDOS}

\begin{tabular}{|c|c|c|c|}
\hline APELLIDO $Y$ NOMBRE & LOCALIDAD & AÑO & SENTENCIA \\
\hline LÓPEZ, Pedro de Juan & ALICANTE & 1554 & - \\
\hline SÁNCHEZ, Pedro & ALMORADÍ (A) & 1554 & Azotes \\
\hline GILABERT, José & CATRAL (A) & 1554 & Azotes \\
\hline MARTÍNEZ, Francisco (S) & ORIHUELA (A) & 1618 & - \\
\hline RUBIO, Luis & ALBATERA (A) & 1649 & - \\
\hline RUIZ, Josefa & ALICANTE & 1673 & - \\
\hline GIL, Andrés & ELCHE (A) & 1675 & - \\
\hline CORAU (f) & ALICANTE & 1679 & - \\
\hline CUCARELLA, Gaspar & ALICANTE & 1679 & - \\
\hline DEITYA, María & MUCHAMIEL (A) & 1679 & Reconciliado \\
\hline BELLOT (S) & VALENCIA & 1679 & - \\
\hline CERDÁN, Crispiliano & VALENCIA & 1679 & - \\
\hline RUIZ, Fernando & MONÓVAR (A) & 1683 & - \\
\hline OLIVARES, Francisco de & ORIHUELA (A) & 1684 & - \\
\hline SALAZIEGO, Juan & NOVELDA (A) & 1713 & - \\
\hline PAZ, Francisco Alfonso de & ALICANTE & 1719 & - \\
\hline SÁNCHEZ, Pablo & CREVILLENTE (A) & 1719 & \\
\hline GONZÁLEZ NAVARRETE, & ORIHUELA (A) & 1742 & - \\
\hline Francisco & GUARDAMAR (A) & 1819 & \\
\hline RODRÍGUEZ SÁNCHEZ, José & & & - \\
\hline
\end{tabular}

